\title{
Developmental Landscape of Potential Vaccine Candidates Based on Viral Vector for Prophylaxis of COVID-19
}

\author{
Rajashri Bezbaruah ${ }^{1 *}$, Pobitra Borah ${ }^{2}$, Bibhuti Bhushan Kakoti ${ }^{1}$, Nizar A. Al-Shar' ${ }^{3}$, \\ Balakumar Chandrasekaran ${ }^{4 *}$, Da'san M. M. Jaradat ${ }^{5}$, Munir A. Al-Zeer ${ }^{6}$ and \\ Saeid Abu-Romman ${ }^{7}$
}

\section{OPEN ACCESS}

Edited by:

Kuldeep Dhama

Indian Veterinary Research Institute

(IVRI), India

Reviewed by:

Khan Sharun,

Indian Veterinary Research Institute

(IVRI), India

Sunil Babu Gosipatala,

Babasaheb Bhimrao Ambedkar

University, India

Birbal Singh,

Indian Veterinary Research Institute

(IVRI), India

*Correspondence:

Rajashri Bezbaruah

rajashribezbaruah@dibru.ac.in

Balakumar Chandrasekaran

balakumar@philadelphia.edu.jo

Specialty section:

This article was submitted to

Molecular Diagnostics and

Therapeutics,

a section of the journal

Frontiers in Molecular Biosciences

Received: 30 November 2020

Accepted: 05 February 2021

Published: 15 April 2021

Citation:

Bezbaruah R, Borah P, Kakoti BB,

Al-Shar'l NA, Chandrasekaran B,

Jaradat DMM, Al-Zeer MA and

Abu-Romman S (2021) Developmental

Landscape of Potential Vaccine

Candidates Based on Viral Vector for

Prophylaxis of COVID-19.

Front. Mol. Biosci. 8:635337.

doi: 10.3389/fmolb.2021.635337
${ }^{1}$ Department of Pharmaceutical Sciences, Faculty of Science and Engineering, Dibrugarh University, Dibrugarh, India, ${ }^{2}$ School of Pharmacy, Graphic Era Hill University, Dehradun, India, ${ }^{3}$ Department of Medicinal Chemistry and Pharmacognosy, Faculty of Pharmacy, Jordan University of Science and Technology, Irbid, Jordan, ${ }^{4}$ Faculty of Pharmacy, Philadelphia University, Amman, Jordan, ${ }^{5}$ Department of Chemistry, Faculty of Science, Al-Balqa Applied University, Al-Salt, Jordan, ${ }^{6}$ Department of Applied Biochemistry, Institute of Biotechnology, Technical University of Berlin, Berlin, Germany, ${ }^{7}$ Department of Biotechnology, Faculty of Agricultural Technology, Al-Balqa Applied University, Al-Salt, Jordan

Severe acute respiratory syndrome coronavirus 2, SARS-CoV-2, arose at the end of 2019 as a zoonotic virus, which is the causative agent of the novel coronavirus outbreak COVID19. Without any clear indications of abatement, the disease has become a major healthcare threat across the globe, owing to prolonged incubation period, high prevalence, and absence of existing drugs or vaccines. Development of COVID-19 vaccine is being considered as the most efficient strategy to curtail the ongoing pandemic. Following publication of genetic sequence of SARS-CoV-2, globally extensive research and development work has been in progress to develop a vaccine against the disease. The use of genetic engineering, recombinant technologies, and other computational tools has led to the expansion of several promising vaccine candidates. The range of technology platforms being evaluated, including virus-like particles, peptides, nucleic acid (DNA and RNA), recombinant proteins, inactivated virus, live attenuated viruses, and viral vectors (replicating and non-replicating) approaches, are striking features of the vaccine development strategies. Viral vectors, the next-generation vaccine platforms, provide a convenient method for delivering vaccine antigens into the host cell to induce antigenic proteins which can be tailored to arouse an assortment of immune responses, as evident from the success of smallpox vaccine and Ervebo vaccine against

\footnotetext{
Abbreviations: AAV, Adeno-associated virus; ACE2, Angiotensin converting enzyme receptor 2; Ad, Adenovirus; AIDS, Acquired immunodeficiency syndrome; COVID-19, Coronavirus disease 2019; EMA, European Medical Agency; FDA, Food and Drug Administration; HA, Hemagglutinin; HIV, Human immunodeficiency virus; HN, Hemagglutinin-neuraminidase; hPIV-1, Human parainfluenza type-1 virus; IFN, Interferon; ITR, Inverted terminal repeats; kb, kilobase; LAIV, Live-attenuated influenza virus; MERS-CoV, Middle East respiratory syndrome coronavirus; MV, Measles virus; MVA, Modified vaccinia virus Ankara; NP, Nucleoprotein; YVAC, New York-attenuated vaccinia virus; PbCS, Circumsporozoite antigen of; Plasmodium berghei; PfCS, Circumsporozoite antigen of Plasmodium falciparum; PROSTVAC, Poxviral prostate-specific Ag-targeting vaccine; R\&D, Research and Development; rMV, Recombinant measles viruses; S proteins, Spike proteins; SARS-CoV, Severe acute respiratory syndrome coronavirus; SARS-CoV-2, Severe acute respiratory syndrome coronavirus 2; SeV, Sendai virus; TAAs, Tumor-associated antigens; TLR, Toll-like receptors; TSAs, Tumor-specific antigens; VACV, Vaccinia virus; VSV, Vesicular stomatitis virus; WHO, World Health Organization.
} 
Ebola virus. As per the World Health Organization, till January 22, 2021, 14 viral vector vaccine candidates are under clinical development including 10 nonreplicating and four replicating types. Moreover, another 39 candidates based on viral vector platform are under preclinical evaluation. This review will outline the current developmental landscape and discuss issues that remain critical to the success or failure of viral vector vaccine candidates against COVID-19.

Keywords: COVID-19, vaccines, viral vector, ChAdOx1-S, Ad5-nCoV, MERS-CoV

\section{INTRODUCTION}

Novel corona virus disease 2020 or COVID-19, caused by the virus severe acute respiratory syndrome coronavirus 2 (abbreviated as SARS-CoV-2), has become an universal outbreak and primary health concern, since its emergence by the end of 2019 in Wuhan, China (Carlos et al., 2020; Guo et al., 2020). The natural host of the virus origin was suspected to be the bats due to higher similarity in genomic sequences, possibly transmitted to humans via an unknown intermediate, further leading to human-to-human transmission through droplets or direct communication (Carlos et al., 2020; Guo et al., 2020). Following swine flu (2009), Ebola in West Africa (2014), polio (2014), Zika (2016), and Ebola in Democratic Republic of Congo (2019) outbreaks, the World Health Organization (WHO) has acknowledged COVID-19 as the sixth public health emergency of global concern (Yoo, 2019). At the time of writing this review, 54, 771, 888 laboratory-confirmed cases and 1,324,249 deaths, owing to this pandemic, had been reported (WHO, 2020f).

Coronavirus is a positive-sense, single-stranded, RNA viruses of the family Coronaviridae; which may affect a broad host range exhibiting symptoms ranging from very mild rhinorrhea to severe fatal illness (Dhama et al., 2020; Kotta et al., 2020). Polygenetic sequencing and evolutionary investigations demonstrated that SARS-CoV-2 is a beta-coronavirus, which displayed $96.2 \%$, $79.5 \%$, and $50 \%$ sequence identity with previously identified bat CoV RaTG13, severe acute respiratory syndrome coronavirus (SARS-CoV), and Middle East respiratory syndrome coronavirus (MERS-CoV), respectively (Jin et al., 2020). Like SARS-CoV, SARS-CoV-2 uses angiotensinconverting enzyme receptor 2 (ACE2) as the entry receptor and manifests similar acute respiratory syndromes (Lee et al., 2006; Iwasaki and Yang, 2020). Despite higher resemblance with the SARS-CoV genome sequence, it shows different transmissibility and diagnosis procedures because of the mutational changes, i.e., existence of a peculiar furin-like cleavage site in the receptor-binding domain of the spike (S) proteins (Coutard et al., 2020). Of importance, continuous mutations in the $S$ protein-encoding genes have allegedly enhanced the virulence capacity of the virus (Q. Li et al., 2020). The replication cycle of SARS-CoV-2 has a close resemblance with SARS-CoV. After transmission of the virus into the human body, it interacts with the host cells via the envelope S proteins. The primary host target receptor for SARS$\mathrm{CoV}-2$ is angiotensin-converting enzyme 2 (ACE2). Binding of the virus to the ACE2 receptor is mediated by $R B D$, and fusion of the virus with the host plasmalemma is mediated by the S2 domain (Yu et al., 2020). Acid-dependent proteolysis by serine 2, cathepsin, and other proteases initiate the trimer cleavage of $S$ protein, which exposes the fusion peptide. The fusion peptide inserts into the host cell membrane and produces the antiparallel 6-helix bundle that results in membrane fusion and releases the viral genome into the cytoplasm of the host cell (Ashour et al., 2020; Badgujar et al., 2020). The uncoated RNA of the virus with ORF1a and $1 \mathrm{~b}$ scrambles viral proteases-processed polyproteins to produce some nonstructural proteins, which produces replication-transcription complex (RTC) inside a doublelayered vesicle. RTC undergoes continuous replication and produces about six-nine subgenomic RNAs (Borah et al., 2021a). These RNAs act as the mRNA template for the translation of structural and accessory proteins. Then S, E, and $M$ proteins undergo translation and insert themselves within the endoplasmic reticulum. Moreover, these proteins produce the mature virus particles by assembling with $\mathrm{N}$ protein-encapsidated viral genome within the endoplasmic reticulum-golgi intermediate compartment. Following these, the virion is transported to the plasmalemma and released by exocytosis (Borah et al., 2021b).

The WHO treatment guidelines recommended isolation of the COVID-19-suspected patients to provide supportive care including immunomodulatory therapy, oxygen therapy, and antibiotics as per requirement (WHO, 2020a). At present, no Food and Drug Administration (FDA)-approved antiviral or immunomodulatory agents are available for the management of the SARS-CoV-2 infection. However, some promising antiviral agents (viz., remdesivir, ritonavir, and lopinavir alone or in conjunction with interferon- $\beta$, favipiravir, etc.), natural products, and some repurposed drugs are under investigation and will be tested through clinical trials (Borah et al., 2020; Dhama et al., 2020; Coronavirus COVID-19, 2020). Without any clear indications of abatement, the disease has become a major healthcare threat across the globe, owing to high prevalence, prolonged incubation period, and absence of existing drugs or vaccines. In order to safeguard the whole global population from continuing danger of morbidity and mortality from SARS-CoV2 , it is crucial to develop and administer an adequate safe and effective vaccine (Awadasseid et al., 2021). In the past decades, many attempts have been undertaken to produce vaccines for human coronaviruses (CoVs) like SARS and MERS, but no approved antiviral therapy or vaccines exists to date. The majority of clinical options available for COVID-19 management are based on prior expertize with the treatment 
of MERS and SARS-CoV (Cyranoski, 2020). Intensive global R\&D efforts have been carried out following the identification of the genetic sequence of SARS-CoV-2 aiming to develop an effective vaccine against the disease (Yadav et al., 2020). However, this can be a long-term practical approach (Zhang et al., 2020b). The use of genetic engineering, recombinant technology and other computational techniques has resulted in several potential candidates for COVID-19 vaccines being produced (Chen et al., 2020; Lundstrom, 2020). As per the WHO, till January 22, 2021, 64 vaccine candidates are under clinical development and 173 candidates are under preclinical evaluation (WHO, 2021). The range of vaccine technology platforms being evaluated, including nucleic acid (DNA and RNA), peptides, virus-like particles, recombinant proteins, liveattenuated viruses, viral vectors (replicating and non-replicating), and inactivated virus approaches, are striking features of the vaccine development landscape for COVID-19 (WHO, 2020b). The majority of vaccines undergoing clinical and preclinical trials involve next-generation vaccine platforms, such as vaccine based on nucleic acid, antigen-presenting cells, or viral vectors (Rauch et al., 2018; van Riel and de Wit, 2020). Succeeding the triumph of Ebola vaccine (Commissioner, 2020), viral vectors can get the appraisal as a valid tool for delivering vaccine into a host cell for generation of antigens that can be tailored to arouse a robust immune response (Bouard et al., 2009; The Scientist, 2020). Furthermore, the promising results of the viral vector-based vaccine candidates against MERS/SARS infections had added a value to this development. This article encompasses brief summary of viral vectors as a potential vaccine development platform, highlights ongoing advances in designing (SelectScience COVID-19 Vaccine, 2021) vaccine candidates based on viral vectors, and also sheds light on the issues that remain critical to the success or failure of viral vector vaccine candidates against COVID-19.

\section{VIRAL VECTOR-BASED VACCINE}

The development of viral vector-based vaccine is a specialized area of in vivo gene therapy. Gene therapy aims to rectify genetic diseases by permanent replacement of a missing or damaged gene with transgene product, introduced via an immune-tolerated carrier vehicle (Ura et al., 2014). Vaccines, on the other hand, aim to provoke a strong immune response against pathogens via introduction of the same pathogenic antigen, along with the supportive inflammatory responses shown by the delivery vehicle. Despite their different aims, gene therapy and vaccines use recombinant viral vectors as a common platform to express therapeutic transgene product and immunogenic antigen, respectively (Ertl, 2016). Followed by extensive research work, the concept of viral vectors has been modified from gene therapy in 1980. Viral vectors are produced by replacing the viral gene with pathogenic transgene or antigen; following administration, the antigen is shuttled into host cells leading to expression of immune responses against that particular pathogen (Rogers et al., 1973; Bouard et al., 2009). In the majority of viral vector-based vaccines, a single dose is adequate for producing a prophylactic action owing to expression of endogenous antigens that stimulate both humoral and cellular immunity (van Riel and de Wit, 2020). Another advantage of viral vector-based vaccines are highly specific targeted gene delivery, improved gene transduction efficiency, enhanced safety and efficacy, and easy large-scale manufacturing (Cai et al., 2020; Creative Biolabs, 2021). Since the explosion of viral vectors as vaccines' development platform, a large number of viral vector-based vaccines have been permitted for veterinary medicine. In 2011, Imojev (vaccine against Japanese encephalitis) was the first approved viral vector-based vaccine for clinical use in humans (Rollier et al., 2011). As a basis for establishing vaccines based on viral vectors, a wide variety of viruses have been used; for example, some commonly used viruses are adenoviruses (Ad), poxviruses, adeno-associated viruses (AAV), parvoviruses, lentivirus, togaviruses, measles viruses, etc. (Ramezanpour et al., 2016). This platform involves viral vectors that can either be replicating (replication-competent), often attenuated, or nonreplicating (replication-defective) (Robert-Guroff, 2007). The replicating vector vaccines infect the host cells, which thereafter give rise to vaccine antigens as well as new viruses that may infect more cells and express immunogenicity. However, nonreplicating vector vaccines are capable of infecting the host cells and produce vaccine antigens but fails to produce new virus particles (van Riel and de Wit, 2020). The storage temperature for viral vector-based vaccines is in-between +2 and $+8^{\circ} \mathrm{C}$ (SelectScience). Figure 1 provides a schematic representation of the development of immune responses against SARS-CoV-2 by replicating and nonreplicating viral vector-based vaccines. A brief description of the commonly used viral vectors is provided below.

\section{Adenovirus (Ad)}

Adenovirus, which is known to cause respiratory tract infections, is a nonenveloped DNA virus having a double-stranded genome of about $30-40 \mathrm{~kb}$ that is enclosed by an icosahedral capsid. It was the first DNA virus to go in diligent therapeutic development with a tremendous interest, mainly because of its high transduction efficiency, genetic stability, wide range of viral tropism, and high expression level of transgenes. In human, 57 serotypes of adenovirus were identified with different tropism mechanism, that are grouped into seven species (A-G) (Seymour and Fisher, 2011; Crystal, 2014; Ura et al., 2014; Lee et al., 2017; Rauch et al., 2018). Ad vaccines are developed by replacement of the genomic regions-early transcript $1 \mathrm{~A}$ and early transcript $1 \mathrm{~B}$ (E1A and E1B) by transgenes. These modifications eliminate the replicating ability of the virus; thereby, they are considered as replicationdefective vectors. Additionally, E3 and E4 genes are often deleted to avoid the abolition of Ad-infected cells by the immune system and to prevent the leaky expression of the inserted transgene, respectively (Wold and Toth, 2013; Rauch et al., 2018). A common method of production of Ad vector involves transfection of plasmid of Ad vector into E1-complementing cell lines (HEK 293 cells), where they infect the cells and undergo replication; newly replicated vectors are collected and subjected to purification using ultracentrifugation (Ura et al., 2014; Ramezanpour et al., 2016). Depending on the employed 


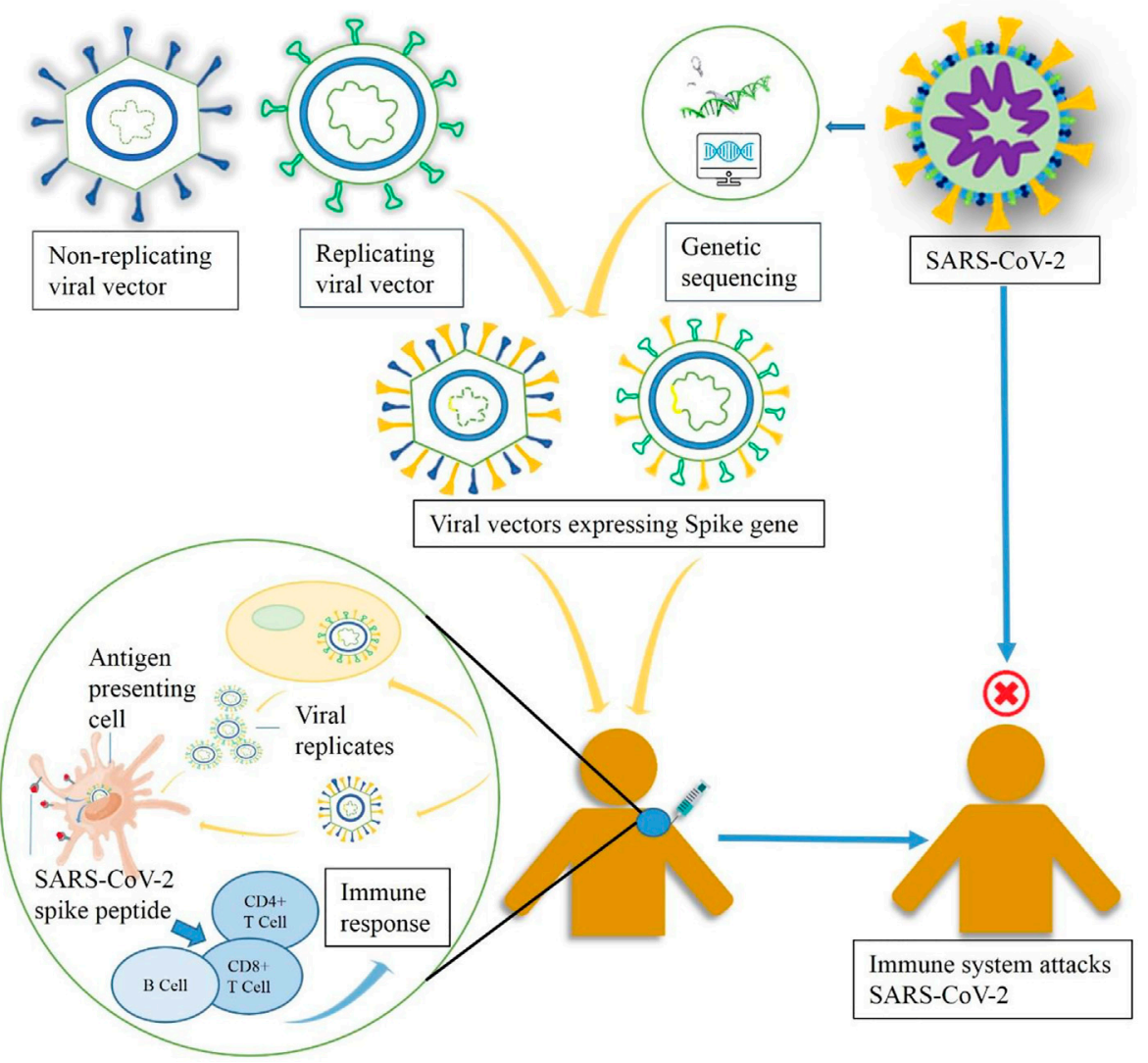

FIGURE 1 | A schematic diagram representing the working principle of replicating and nonreplicating viral vector-based vaccine candidates expressing the spike protein of SARS-CoV-2.

serotype, Ad vectors can induce both cell-mediated and antibodymediated immunity with a variation in immune response (Humphreys and Sebastian, 2018). Replication-deficient human Ad serotype (Ad5) can be easily produced in high titers, so they possess a great attraction as a gene delivery vector (Tan et al., 2013; Ura et al., 2014). Nevertheless, preexisting immunity of the immunized person may obstruct the clinical use of this virus. In order to overcome this limitation, adenoviral vectors had been developed from nonhuman origin, for example, the chimpanzee virus-derived vector ChAd63. Moreover, selection of rare serotypes with reduced risk in human (viz. Ad26 or Ad 35) is an alternative way to overcome the resistance (Rauch et al., 2018; Buchbinder et al., 2020).

\section{Poxviruses}

Poxviruses are the most extensively studied viral vectors. In 1978, vaccinia virus (VACV, a Poxvirus family member) was found to be successful for eradicating small pox virus (Jenner, 1988). It is a huge, complex, and enveloped double-stranded DNA virus. The size of the DNA genome is approximately $190 \mathrm{~kb}$ in length, and it accepts about $25 \mathrm{~kb}$ of antigen (Jacobs et al., 2009). Numerous highly attenuated VACV strains are available for use in humans and animals, which includes both replication-competent and replication-deficient strains (Ura et al., 2014). One of the most commonly used, well-characterized VACV strains is a replication deficient-attenuated VACV called modified vaccinia virus Ankara (MVA), which is constructed by the removal of $15 \%$ vaccinia genome by sequential passaging through chicken embryo fibroblasts (Sutter and Staib, 2003). Some other examples of replication deficient strains are New York-attenuated vaccinia virus or NYVAC (derived from Copenhagen strain of vaccinia), ALVAC (avipox vectors: canarypox), and FPV (fowlpox) (Franchini et al., 2004; Parrino and Graham, 2006). Vaccines based on vaccinia virus shows high-transgene expression and thus can produce a robust immunity against antigens. Moreover, they induced innate immunity facilitated by the inflammasome and Toll-like receptors (TLRs). One limitation of vaccinia vaccine is that the efficacy may be affected by preexisting immunity (Cooney et al., 1991; Ura et al., 2014).

\section{Measles Virus (MV)}

Measles virus belonging to Paramyxoviridae family is an enveloped RNA virus, with a single-stranded, nonsegmented, negative-sense genome of approximately $16 \mathrm{~kb}$. MV vaccine is produced by repetitive serial passage of infectious virus via various cell lines that results in a live-attenuated and 
replication deficient virus. The process undergoes numerous mutations that makes MV vaccine genetically stable; moreover, retrogression to pathogenicity has never been detected (Zuniga et al., 2007). Additionally, the virus is unable to merge into the host genome, and thermostability of the virus has been established by lyophilization. With all these advantages, MV vaccine shows extremely durable immunization induced by both humoral- and cell-mediated immune response (Ovsyannikova et al., 2003; Tangy and Naim, 2005). Unlike adenoviral vector (where T-cell-mediated response is dominated by $\mathrm{CD}^{+}$phenotype), MV shows $\mathrm{CD} 4^{+}$dominated T-cell-mediated response, and that may be a consideration for vaccine generation (Rauch et al., 2018). MV is a valuable promising vaccine delivery system because of efficient transgene expression aptitude and low production cost, and most significantly, MV genome has the capability of stable insertion of more than 5,000 nucleotides (Zuniga et al., 2007; Loessner et al., 2012). Owing to its ability to withstand relatively large transgenes, multipathogen or multivalent MV-based vaccines can be produced (Lauer et al., 2017). Furthermore, antivaccine efficacy of MV vaccine is not compromised by the vector immunity (Ramsauer et al., 2015).

\section{Sendai Virus (SeV)}

Sendai virus is a single-stranded, negative-stranded, nonsegmented, enveloped RNA virus, which is a member of Paramyxoviridae family (Nakanishi and Otsu, 2012). SeV is found to be nonpathogenic in humans, but it causes bronchopneumonia in mice (Ura et al., 2014). SeV is found to have high resemblances with the human parainfluenza type-1 virus (hPIV-1), and thus, activity of the SeV vector is affected by preexisting host immunity against hPIV-1. Cell entry and tropism of the $\mathrm{SeV}$ genome are mediated by two enveloped glycoproteins, namely, hemagglutinin-neuraminidase (HN) and fusion glycoprotein FO (F). Deficiency of these proteins generates replication-defective virus and advances vector's safety (Ura et al., 2014). In the first generation of $\mathrm{SeV}$ vectors, replicationcompetent vectors were produced by installing exogenous cDNA in the full-length $\mathrm{SeV}$ genome. However, for practical applications, replication-defective $\mathrm{SeV}$ vectors were produced by transfecting the packaging cell with a genome in which $\mathrm{F}$ gene has been replaced with transgene. The $\mathrm{SeV}$ vector can transduce both dividing as well as nondividing cells. It contains viral genome and RNA-dependent RNA polymerase in their cytoplasm, which ensures genotoxic advantages of the virus. It also confirms fast gene expression following an infection. Its transgene capacity (i.e., $3.4 \mathrm{~kb}$ ) is low compared to the other viral vectors (Nakanishi and Otsu, 2012; Ura et al., 2014).

\section{Adeno-Associated Virus (AAV)}

Adeno-associated virus is a member of Parvoviridae family, which is a small, nonpathogenic, nonenveloped, singlestranded DNA virus (Romano, 2005). The virus shows low immunogenicity as it contains only two genes that can be replaced with transgene, and for replication, it is dependent on helper virus functions. The genome size of AAV is $4.7 \mathrm{~kb}$, and once infected a human cell, it integrates with human genome at a specific site on $19 \mathrm{q}$ chromosome. The integration includes the inverted terminal repeats (ITR) and Rep region at both terminals of the viral genome, providing a high level of expression. Furthermore, the virus shows wide tropism and can infect both dividing and nondividing cells (Johnson et al., 2005; Liniger et al., 2007; Ura et al., 2014). There are 12 AAV serotypes available to be used in humans, of which AAV2 is mostly used in clinical and preclinical practices. More than 100 serotypes of AAV are found in various animal species. Each serotype has own receptor and tissue specificity (Xiao et al., 1999). Recombinant AAV vectors are produced by replacing Cap and Rep regions between the ITRs with transgenes. Following these modifications, AAV vectors cannot integrate into the host genome (Ura et al., 2014). AAV vector has low-titer production efficiency in comparison to other viral vectors. To compensate for this limitation; large-scale, highly efficient production has been developed (Urabe et al., 2002; Ura et al., 2014). After transducing the host cell, AAV provoke innate immune response and produce interferon (IFN) $\alpha / \beta$. In Kupffer cells, induction of TLR9- and TLR2-dependent cytokine expression was also observed. AAV produces mild humoral- and cell-mediated immune response. Besides, immunogenicity is affected by preexisting immunity and neutralizing antibodies, thus AAV vector-based vaccines are rarely used in clinical trials. Several recombinant, randomly mutant or hybrid recombinant AAV are produced to improve the efficacy of AAV for vaccine development (Cai et al., 2020).

\section{VIRAL VECTORS AS A PROMISING PLATFORM FOR SOME OF THE DEADLIEST DISEASES}

\section{Smallpox}

Smallpox disease caused by variola virus was a contagious disease that claimed millions of lives till the time of its eradication (Fenner et al., 1988; Parrino and Graham, 2006). The worldwide eradication of variola virus was a tremendous success that was achieved by the introduction of VACV vaccine. In 1796, Edward Jenner, an English doctor, has experimented the use of cowpox virus against small pox; then, it was followed by a good number of experiments in 1801, where Jenner published his discoveries. Soon after that, vaccination became widely accepted, and at some point in the 1800s, the cowpox virus has been replaced with vaccinia virus (VACV) (CDC, 2019). In order to have cross-protection against Variola virus, VACV was used for nearly 2 decades until the obliteration of smallpox in the late 1970s. Though the origin of VACV remains unidentified, it is mostly related to horsepox virus (Tulman et al., 2006). Most of the vaccines were developed on living animal's skin like calves, sheep, rabbits, and buffalos. During the eradication program, various vaccinia virus strains, such as Lister (Elstree), the New York City Board of Health (NYCBH), Copenhagan, and Ankara MVA strain had been used for the development of vaccines (Parrino and Graham, 2006; Jacobs et al., 2009). As vector, Jennerian vaccine viruses (viz., Dryvax, Lister, and Copenhagan) signify the first generation of 
VACV vaccines. Second generation of VACV includes tissue culture-adapted Jennerian. Since the time of eradication, continued research on several strategies such as genetic engineering of immunomodulatory proteins-encoded viral genes, and serial passage in an alternative host have developed several modified VACV vaccines with enhanced safety profile. At present time, third and fourth generation of VACV attenuated by passage in an alternate host and genetic engineering, respectively, are considered for stockpiling in opposition to a potential revive of smallpox by bioterrorism. The propensity of the VACV genome to accumulate new genetic material allows researchers to develop new vaccines against a broad variety of contagious diseases (Jacobs et al., 2009).

\section{Influenza}

Influenza (the flu) caused by the virus influenza is a contagious disease. Moreover, influenza is a source of several respiratory tract infections, and it causes annual epidemics. Though the infection is self-limiting, it may develop severe complications in certain patient groups that may be lethal (Medina and García-Sastre, 2011). Several vaccine formulations are available against circulating influenza strains. Viral vectors are also used for influenza vaccine production. Soon after the success of vaccinia virus for eradicating small pox disease, recombinant vaccinia viruses were designed as a viral vector vaccine to express antigens of influenza virus. Smith et al. generated the first viral vector expressing the influenza hemagglutinin (HA) gene, and that vaccine was able to produce protective immune response in animal models (Smith et al., 1983). After this, various recombinant viral vector vaccines expressing different influenza virus proteins like NP, M1, PA, NA, PB1, and PB2 were designed (Smith et al., 1987; de Vries and Rimmelzwaan, 2016). Modified vaccinia virus Ankara (MVA) vector is produced by sequential passing of chorioallantois vaccinia virus Ankara through fibroblast of chicken embryo (Mayr and Munz, 1964). Other attenuated poxviruses such as NYVAC (Kyriakis et al., 2009), raccoonpox (Kingstad-Bakke et al., 2012), canarypox (Minke et al., 2007), and fowl-pox (Taylor et al., 1988) have been used as viral vectors for the development of influenza vaccine candidates. Furthermore, several other viruses like recombinant herpes virus, alpha virus, vesicular stomatitis virus, baculovirus, Newcastle disease virus, and adenovirus vectors were also used to generate vaccine against influenza virus (de Vries and Rimmelzwaan, 2016).

\section{Malaria}

Malaria, affecting billions of people globally, is a significant factor of mortality and morbidity. Viral vectors are outstanding vector vehicle for malarial antigens. For the transmission of malaria antigens classic viral vectors like adenovirus, alphavirus, and poxvirus vectors have been successfully used (Li et al., 2007). In a phase I/II clinical trial, a multi-stage, multi-antigen, poxvirus-vectored vaccine candidate NYVAC-Pf7 had showed low-titer immune response against malaria infection (Ockenhouse et al., 1998). Other attenuated poxviruses like MVA tend to be less efficient in priming immune response, but is best at immune response boosting. However, in conjunction with other vectors or protein/DNA-based vaccines, a VACV vector is likely to be helpful as heterologous prime-boosting regimens (Schneider et al., 1998). For example, heterologous prime boost immunization with Chimpanzee adenovirus 63 and modified vaccinia Ankara encoding thrombospondin-related anonymous protein (ChAd63 MV A ME-TRAP) found to be safe and immunogenic vaccine regimen against malaria, though protection efficacy is not significant (Ogwang et al., 2015; Bliss et al., 2018; Tiono et al., 2018). New emerging vectors like measles virus, yellow fever virus, and vesicular stomatitis virus (VSV) offer supplementary opportunities for designing malaria vaccine candidates ( $\mathrm{Li}$ et al., 2007). A preclinical investigation of a malaria vaccine candidate based on recombinant measles viruses (rMV) expressing PbCS (circumsporozoite antigen of Plasmodium berghei) and PfCS (circumsporozoite antigen of Plasmodium falciparum) demonstrated induction of high-antibody response in mice that remain for at least 22 weeks post-prime. The vaccine candidate also confirmed rapid development of cellular immunity (Mura et al., 2019).

\section{Cancer}

In the field of cancer research, the aim of cancer vaccine is to induce strong and durable effective immune response against self-antigens which are tumor-associated antigens (TAAs) and tumor-specific antigens (TSAs) (Guo et al., 2013). Various strategies have been proposed to develop therapeutic cancer vaccines, among which viral vector platform is showing promising results. IMLYGIC, the first oncolytic viral therapy approved in the US, is based on a genetically modified herpes simplex type- 1 virus (FDA, 2019). Poxviral vectors or its prototype VACV are among the mostly used viruses in the production of cancer vaccines (DeMaria and Bilusic, 2001). A randomized phase II trial of PROSTVAC (a poxviral prostate-specific Ag targeting vaccine) in men suffering from metastatic castrationresistant prostate cancer demonstrated an increase in overall patients survival. However, a recent phase III study concluded that PROSTVAC induce T-cells that have the capability of tumor infiltration but the T-cell-mediated immune response does not translate into therapeutic benefit. The study results suggested that poxvirus can be a promising platform when used with different antigen targets, in combination with checkpoint inhibitor, or in other disease settings (Gulley et al., 2019). Adenoviruses, when used in animal models (Lundstrom, 2017), have shown potential therapeutic effects for gastric cancer, hepatic carcinoma, prostate (Ekblad and Halldén, 2010), ovarian (Matthews et al., 2009), and brain cancer (Fu et al., 2010). Shapira et al. demonstrated that adenoviral vectors encoding a proapoptotic PUMA gene regulated by RAS-responsive elements (Ets/AP1) can suppress the growth of cancer cell with KRAS mutation (Shapira et al., 2017). In addition to the abovementioned vectors, several other viral vectors including AAV, lentivirus, Newcastle disease virus, measles virus, rhabdo viruses, and baculo viruses are being engineered for cancer vaccine development (Lundstrom, 2017). 


\section{Ebola}

Ebola hemorrhagic fever caused by Ebola virus is one of the deadliest viral disease affecting humans and nonhuman primates worldwide. In response to 2014 outbreak, Ebola has been acknowledged as a public health emergency of international concern by WHO (2020c). Responding to this emergency, vaccine development against Ebola was accelerated. Several replicating and nonreplicating viral vectors such as alphavirus, flavivirus, adenovirus, vaccinia virus, and paramyxovirus have been used for vaccine development. Of these, two prime candidates have emerged, namely, the chimpanzee adenovirus-based vaccine (ChAd3-EBO-Z) (Tapia et al., 2015) and the recombinant vesicular stomatitis virus-based vaccine (rVSVAG-ZEBOV-GP) (Piszczatoski and Gums, 2020). Another candidate consisting of an adenovirus type 26 vector vaccine encoded with glycoprotein of Ebola (Ad26.ZEBOV), and a modified vector vaccine of vaccinia Ankara (MVA-BN-Filo) have shown promising results (WHO, 2018) and is in phase III clinical trial (ClinicaltrialsNCT04556526, 2020L). Recently, the European Medicines Agency has proposed the marketing authorization of the vaccine Ad26.ZEBOV/MVA-BN-Filo to be given in the European Union (EMA, 2020). rVSVAG-ZEBOVGP or Ervebo is a recombinant, live, replication-competent, attenuated vaccine comprising a backbone of the vesicular stomatitis virus (VSV), which is modified to express a Zaire Ebolavirus glycoprotein to produce the neutralizing immune response of a host to the Ebola virus. Ervebo is given as a single dose. After tremendous research work, Ervebo was approved by the FDA as the first vaccine against Ebola. The approval was published on December 19, 2019, and the medication is under postmarketing surveillance by the European Medical Agency (EMA) (Piszczatoski and Gums, 2020).

\section{AIDS}

The human immunodeficiency virus (HIV), the causative organism of acquired immunodeficiency syndrome (AIDS), weakens the immune system against several infectious conditions, including some types of cancer (WHO, 2020d). Over $30 \mathrm{HIV} / \mathrm{AIDS}$ vaccine candidates with positive response in nonhuman primate models have progressed to clinical trial either alone or in combination (Ross et al., 2010). Among which viral vectors is the most promising way to deliver HIV immunogens for induction of cellular immunity to HIV. Additionally, prime-boost strategies of viral vectors had shown promising results. Many viral vector-based HIV vaccine candidates are under clinical and preclinical investigation, including adenovirus, poxvirus, alpha virus, and adenoassociated virus, in addition to combination of viral vectors encoding HIV gene (Sauter et al., 2005). For the first time, RV-144 in a phase III efficacy clinical trial in Thailand had shown that HIV infection can be prevented by vaccination. This trial assessed the effectiveness of four priming immunizations of ALVAC-HIV (vCP1521) in combination with two booster injections of a recombinant gp120 subunit vaccine (AIDSVAX B/E) (Rerks-Ngarm et al., 2009; Pantaleo et al., 2010). Another phase I clinical trial had demonstrated that upon single administration, MVA-B, a poxvirus-based HIV/ AIDS vaccine candidate triggers a robust, polyfunctional, long lasting T-cell response against HIV-1infection in human (Gómez et al., 2011). A preclinical study had confirmed that dendritic cell vaccine based on lentiviral vector can supress the replication of HIV in improved mice model (Norton et al., 2019).

\section{HISTORY OF VIRAL VECTOR-BASED VACCINES DEVELOPMENT AGAINST SARS AND MERS-COV}

Around the year 1960, the first endemic coronavirus infection was recognized. Till date, total seven coronavirus infections including SARS-CoV-2 has been identified, among which four (viz. HCoV-229 E, HCoV-NL63, $\mathrm{HCoV}-0 \mathrm{C} 43$, and $\mathrm{HCoV}-$ HKU1) were known to cause endemic by triggering minor diseases like common cold or flu in immune-compromised populations (Corman et al., 2018). Another two epidemic coronavirus infections emerged around 2002 and 2012, known as SARS-CoV and MERS-CoV, respectively, also exhibited flulike symptoms and fatal acute respiratory infections (Badgujar et al., 2020). Isolation and phylogenetic examination of the newly emerged coronavirus (SARS-CoV-2), responsible for causing COVID-19, showed similarity with SARS-CoV virus; thus, the new virus is referred to as SARS-CoV-2 (Lu et al., 2020). So far, no vaccines are available against human coronavirus infections, though dozens of coronavirus vaccine candidates are being evaluated; subsequently, the epidemic of SARS-CoV and MERS-CoV is in preclinical and early clinical studies. Spike (S) glycoprotein was used as a target antigen in most of the cases. However, one SARS-CoV and four MERS-CoV vaccine candidates were advanced to early clinical trial, and those are based on $S$ protein. It has been assumed that, in case of SARS$\mathrm{CoV}$, owing to fast disappearance of the virus, only one vaccine has completed phase I trial and other two trials were withdrawn. Notably, three of these potential MERS/SARS vaccine candidates are from viral vector platform, while the other two are DNAbased vaccine (Zhang et al., 2020a). Human Ad-vector, chimpanzee Ad-vector, and MVA-vector have been employed for designing BVRS-GamVac (ClinicaltrialsNCT04130594, 2019), ChAdOx1MERS (MERS001) (ClinicaltrialsNCT03399578, 2018a), and MVA-MERS-S (ClinicaltrialsNCT03615911, 2018b) vaccines, respectively. Guo et al. reported that single intramuscular immunization of mice with recombinant human adenoviral (type 5 or 41 ) vector vaccine encoded with full-length $S$ protein of MERS-CoV can produce mucosal T-cell-mediated immune response and systemic neutralizing antibodies. However, T-cell-mediated immunity is not observed in case of intragastric route administration (Guo et al., 2015). Intriguingly, the vector rAd5 encoded with shorter S1 extracellular domain of S protein had manifest slightly stronger neutralizing antibody responses than full-length $S$ protein. This signifies the effect of immunofocusing (Kim et al., 2014). Hashem et al. (2019) had established that rAd5 expressing CD40-targeted S1 fusion protein (rAd5-S1/F/ $\mathrm{CD} 40 \mathrm{~L}$ ) provide a total protection against MERS-CoV in the 
hDPP4 transgenic mice model and also prevent pulmonary perivascular hemorrhage (Hashem et al., 2019). Currently, phase I and phase II clinical trials are in progress for BVRSGamVac (a human Ad-vector-based vaccine candidate against MERS-CoV) with the aim to assess safety and immunogenicity (NCT04130594).

Chimpanzee adenovirus due to deficiency of preexisting immunity and attractive safety profile represents a good alternative to human adenoviral vector (Dicks et al., 2012). METRS001, a ChAdOx1 vaccine candidate encoding MERS$\mathrm{CoV} S$ protein, has recently completed phase I, nonrandomized, dose-escalation, uncontrolled, open-label trial, and at all tested doses, was found to be safe and welltolerated. Furthermore, a single dose was capable of eliciting both cellular and humoral immunity against MERS-CoV (Folegatti et al., 2020).

The full-length $S$ protein-encoded recombinant MVA also represents a promising vaccine candidate for MERS-CoV, owing to its better immunogenicity, high safety, and protective profile for MERS-CoV (Song et al., 2013; Volz et al., 2015). A MVAbased vaccine candidate, MVA-MERS-S, is currently under phase-I human trial, where the safety and immunogenicity of the vaccine will be investigated in healthy adults (NCT03615911). Recently, another report of recombinant MVA vaccine expressing the $\mathrm{S}$ protein of MERS-CoV confirmed safety and immunogenicity against MERS-CoV upon intramuscular administration in a phase I clinical trial (Koch et al., 2020). Nevertheless, MVA encoding highly conserved $\mathrm{N}$ protein along with S protein of MERS-CoV found to provoke $\mathrm{CD}^{+}{ }^{+} \mathrm{T}$-cell response, but the protecting efficacy is not yet investigated (Veit et al., 2018). Apart from these, MERS-CoV's vaccine based on Newcastle disease virus (NDV) can induce neutralizing antibodies in Bactrian camels and BALB/c mice (LIU et al., 2017). Another live-attenuated measles virus-based vaccine

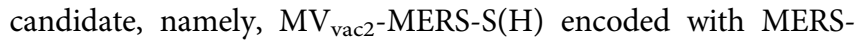
$\mathrm{CoV}$ spike glycoprotein, had shown multifunctional cellular immunity in preclinical study (Bodmer et al., 2018). Currently, a list prepared by WHO showed eight viral vector-based SARS$\mathrm{CoV}$ vaccine candidates under preclinical investigation (WHO, 2020e).

In the current set-up, the preceding understandings of coronavirus vaccine development such as immunogenic response, antigen, challenges while using animal models, adjuvants, and route of administration may add some supplementary role in the rapid development of a vaccine against COVID-19. Viral vector-based vaccine candidates are second-generation vaccines in antiviral vaccine development strategies and more beneficial compared to first generation vaccine because they vaccinate the live virus into a nonvirulent vector by recombining the antigenic protein component of pathogenic virus. Thus, it imitates the possible natural pathogenic contamination, followed by humoral and cellular immunity (Yong et al., 2019; Badgujar et al., 2020; Zhang et al., 2020a; Zhang et al., 2020b).

Regalado et al. have mentioned some explanations for the shortage of reliable and commercial vaccines against SARS and MERS-CoV. With MERS-CoV, vaccine development, it is likely to be delayed due to the shortage of appropriate and productive small animal model during preclinical study. Another cause may be the lack of interest to invest in a vaccine for a comparatively low and geographically centralized disease as compared to other more chronic and global infectious diseases (HIV, measles, and tuberculosis). On the other hand, SARS-CoV cases ceased to be reported in 2004, and thus, further investigation in SARS-CoV's vaccine was assumed to be futile (Padron-Regalado, 2020).

\section{COVID-19 AND VIRAL VECTOR-BASED VACCINE PLATFORM}

In current scenario, the ongoing COVID-19 pandemic has greatly accelerated the requirement of a massively producible, safe, and efficient vaccine for SARS-CoV-2. In such instance, vector-based vaccines have come as the front-runner. As illustrated by successful eradication of smallpox (Ura et al., 2014), FDA approval of Ervebo (CDC, 2020), and other promising vaccine candidates against various infectious diseases, viral vectors offer themselves as an attractive platform for the development of vaccines against COVID-19. Additionally, the lesson acquired from the viral vector-based vaccine development strategies for MERS and SARS-CoV have also provided a high benefit for rapid designing of COVID-19 vaccine.

As per draft landscape of COVID -19 candidate vaccines published by the WHO on 22nd January 2021, 10 nonreplicating and 4 replicating (overall 14) viral vector-based vaccine candidates are under clinical evaluation. Nevertheless, a total of 39 are under preclinical trial, among which 20 are nonreplicating and 19 are replicating viral vectors. The vaccine development program for COVID-19 had used a wide spectrum of vectors including Ad, MVA, Sendai viruses, parainfluenza viruses, rabies viruses, influenza viruses, and Newcastle viruses. Intramuscular route is the preferable route of administration for most of the vaccine candidates. Four adenovirus-based vaccine candidates (ChAdOx1-S, adenovirus type 5 vector, adeno-based $(\mathrm{rAd} 26+\mathrm{rAd} 5-\mathrm{S})$, and $\left.\mathrm{Ad} 26 \mathrm{CoVS}_{1}\right)$ have reached phase III of clinical trial (WHO, 2021). A complete list of viral vector-based COVID-19 vaccines under clinical trial is given in Table $\mathbf{1}$.

\section{Vaccines Under Phase III Clinical Development ChAdOx1-S}

The ChAdOx1-S or ChAdOx1 nCoV-19 is a nonreplicating viral vector-based vaccine candidate for COVID-19 designed by the University of Oxford in collaboration with AstraZeneca (Ledford, 2020). It is presently known as AZD1222 and is presently undergoing phase III human trial. Upon the emergence of SARS-CoV-2, one of the promising vaccine candidates for MERS-CoV, ChAdOx1 MERS has been repurposed, and AZD1222 encoding a full-length codon-optimized S protein of SARS-CoV-2 has been designed. ChAdOx1 is an isolate Y25derived replication-deficient simian adenoviral vector (Precision vaccination, 2020c). As reported by Dicks et al., in the human 
TABLE 1 | List of viral vector-based COVID-19 vaccines under clinical trial (WHO, 2021).

\begin{tabular}{|c|c|c|c|c|}
\hline Vaccine & Route & Phase & Sponsor(s) & Clinical trial ID \\
\hline \multicolumn{5}{|c|}{ Nonreplicating viral vector-based vaccine } \\
\hline \multirow[t]{5}{*}{ AZD1222 (ChAdOx1-S) } & $\mathrm{IM}$ & III & University of Oxford & ISRCTN89951424 \\
\hline & & & AstraZeneca & NCT04516746 \\
\hline & & & & NCT04540393 \\
\hline & & & Serum Institute of India Pvt. Ltd & CTRI/2020/08/ \\
\hline & & & & 027170 \\
\hline \multirow[t]{2}{*}{ Adenovirus type 5 vector } & $\mathrm{IM}$ & III & CanSino Biological Inc & NCT04526990 \\
\hline & & & NPO Petrovax & NCT04540419 \\
\hline \multirow[t]{2}{*}{ Gam-COVID-vac } & $\mathrm{IM}$ & III & Gamaleya Research Institute & NCT04530396 \\
\hline & & & & NCT04564716 \\
\hline Ad26.COV-S (JNJ-78436735, & $\mathrm{IM}$ & III & Janssen Vaccines and Prevention B.V. & NCT04505722 \\
\hline \multicolumn{4}{|l|}{ Ad26COVS1) } & NCT04614948 \\
\hline hAd5-S-Fusion + N-ETSD & SC & I & ImmunityBio, Inc & NCT04591717 \\
\hline GRAd-COV2 & $\mathrm{IM}$ & 1 & ReiThera Srl & NCT04528641 \\
\hline Ad5-nCoV & $\mathrm{IM}$ & 1 & Institute of Biotechnology, Academy of Military Medical Sciences, PLA China & NCT04552366 \\
\hline VXA-CoV2-1 & Oral & I & Vaxart & NCT04563702 \\
\hline MVA-SARS-2-S & $\mathrm{IM}$ & I & University Medical Center Hamburg-Eppendorf & NCT04569383 \\
\hline AdCOVID & $\mathbb{I N}$ & & Altimmune & NCT04679909 \\
\hline \multicolumn{5}{|l|}{ Replicating viral vector-based vaccine } \\
\hline \multirow[t]{2}{*}{ DelNS1-2019-nCoV-RBD-OPT1) } & $\mathbb{I N}$ & $\|$ & Beijing Wantai Biological & ChiCTR2000039715 \\
\hline & & & Pharmacy and Xiamen University & \\
\hline IIBR-100 & IM & $\|$ & Israel Institute for Biological Research & NCT04608305 \\
\hline V590 & $\mathrm{IM}$ & I & Merck Sharp and Dohme & NCT04569786 \\
\hline COVID-19-101 & IM & I & Institute Pasteur & NCT04497298 \\
\hline
\end{tabular}

aIM: intramuscular, IN: intranasal, and SC: subcutaneous.

population the seroprevalence of antibodies to $\mathrm{Y} 25$ is $0 \%$ in the United Kingdom and 9\% in Gambia (Dicks et al., 2012). Preclinical study in mice and rhesus macaques demonstrated that AZD1222 can elicit a strong cell-mediated and humoral immune response. As per the report, AZD1222 can induce a stable Th1/Th2 humoral and cellular response, and a significant reduction of viral load in the lower respiratory tract tissue and broncho alveolar lavage fluid as compared to control. Notably, no evidence of pneumonia and immune-enhanced diseases were detected in immunized animals (van Doremalen et al., 2020). A preliminary phase I/II study report of AZD1222 published on July 20, 2020, showed an acceptable safety profile, high immunogenicity and tolerability of the vaccine candidate. However, the reduction in reactogenicity was observed with paracetamol and following second dose. The study also observed a four-time increase in antibodies to $S$ protein of SARS-CoV-2 in 95\% of subjects, after one month of AZD1222 single dose injection (Folegatti et al., 2020). Clinical development of AZD1222 has progressed worldwide with late-stage phase II/III clinical trials in various countries including the United Kingdom (ISRCTN89951424), the United states (ClinicaltrialsNCT04516746, 2020e), Russia (ClinicaltrialsNCT04540393, 2020i), and India (ClinicaltrialsCTRI/2020/08/027170, 2020). In India, AZD122 is dubbed as Covishield (Times Now Digital, 2020). As of September 12, 2020, as part of the clinical trial, 18,000 individuals have received AZD1222 worldwide. As per AstraZeneca, following safety and efficacy assessment, 300 million doses of AZD1222 will be available by July 2021 (CEPI, 2020). A study report published on January 9th, 2021, confirmed the safety profile of AZD1222 and proved to be efficacious against symptomatic treatment of SARS-CoV-2 infection (Voysey et al., 2021).

\section{Adenovirus Type 5 Vector Vaccine}

CanSino Biological Inc. and Beijing Institute of Biotechnology are developing a adenovirus type 5 vector vaccine, which is a replication-defective adenovirus type-5 (Ad5) vector expressing the S glycoprotein of SARS-CoV-2 strain (Precision vaccination, 2020a; Zhu et al., 2020b) A non-randomized, single-centered, dose-escalation, open-label, phase I trial for adenovirus type 5 vector vaccine was performed on healthy adults (18-60 years) in Wuhan, China. The study results found adenovirus type 5 vector vaccine to be immunogenic and tolerable in healthy adults and can produce both humoral (at day 28 postvaccination (Precision vaccination, 2020b) and cellular (from day 14 after single dose) immunity against SARS-CoV-2. Among the three doses group, high dose of the vaccine shows more immunogenicity compared with the middle and low dose. However, the high dose was associated with higher reactivity, and some adverse effects such as severe fever, dyspnea, fatigue, joint pain, and muscle pain were also reported (Zhu et al., 2020b). Following this, a placebo-controlled, double-blind, randomized, phase II study was performed, which extended the knowledge of the immunogenicity and safety of the adenovirus type 5 vector vaccine. Older population showed higher tolerability but lower immune response than younger population and thus the study assumed that a supplementary dose might be required for older population. Except mild, transient vaccination-related adverse effects no serious adverse effects were detected. In majority of the recipients, immunization with single dose of the vaccine induced rapid onset of immunity within 14 days and significant humoral 
and cellular immunity within 28 days. For further evaluation of efficacy, this phase II trial support experimenting adenovirus type 5 vector vaccine at $5 \times 10^{10}$ viral particles in a phase III effectiveness trial in healthy adults (Zhu et al., 2020a). Till date, two phase III clinical trial has been registered in ClinicalTrials.gov. A double-blind, placebo-controlled phase III study sponsored by CanSino Biologics Inc. has started on 15 September 2020 with the aim to evaluate immunogenicity, safety, and efficacy of adenovirus type 5 vector vaccine in healthy volunteers (18 years or above) (ClinicaltrialsNCT04526990, 2020f). Another randomized, double-blind phase III trial started on 11 September 2020 was sponsored by NPO petrovax, that will assess the efficacy, safety, and reactogenicity of the vaccine compared with placebo in total of 500 healthy subjects (age from 18 to 85 years) (ClinicaltrialsNCT04540419, 2020j).

\section{Gam-COVID-VacLyo}

The vaccine candidate Gam-COVID-VacLyo is being developed by Gamaleya Research Institute which consists of two recombinant adenovirus vector components, type 26 (rAD26) and type 5 (rAd5), and both encoding with $S$ glycoprotein of SARS-CoV-2 virus (rAD26-S and rAD5-S). Safety and immunogenicity assessment of lyophilized and frozen formulation of this vaccine was examined in two phase I/II clinical trials on healthy adults (18-60 years aged) at two Russian hospitals. Safety of the two individual components of the vaccine candidate Gam-COVID-VacLyo was established in phase I trial. Then, in phase II, as a prime-boost vaccination, both components were injected intramuscularly and it showed that the vaccine had a good tolerability and generate strong cellular and humoral immune responses in the subjects. Moreover, antibody titers were higher in vaccinated subjects than those in convalescent plasma. Postvaccination antibodies were increased significantly from day 14 and cellular immunity was peaked at day 28. Additionally, the vaccine did not cause any serious adverse events in healthy adult participants (Logunov et al., 2020). Recently, an open-ended prospective nonrandomized phase II study has started with 110 volunteers over the age of 60 , with the goal to assess tolerability, safety, and immunogenicity of Gam-COVID-VacLyo (ClinicaltrialsNCT04587219, 2020q). On September 7, 2020, a phase III clinical trial has been started with the official title "Randomized Double-Blind Placebo-Controlled Multi-Center Clinical Trial in Parallel Assignment of Efficacy, Safety, and Immunogenecity of Gam-COVID-Vac Combined Vector Vaccine in SARS-CoV-2 Infection Prophylactic Treatment." This trial will involve a total of 40,000 participants over the age of 18 years, and they will be randomized (3:1) into placebo receiving reference group (10,000 subjects) and test group (30,000 subjects). This study has been sponsored by Gamaleya Research Institute in collaboration with Government of the City of Moscow and CRO: Crocus Medical BV (ClinicaltrialsNCT04530396, 2020h). Another phase III trial has started on September 28, 2020, in Belarus, which has also been sponsored by Gamaleya Research Institute in collaboration with Russian Direct Investment Fund and CRO: iPharma; it is a double-blind, multicenter, placebo controlled randomized, phase III trial for assessment of efficacy, immunogenicity, and safety of the vaccine candidate Gam-COVID-VacLyo against COVID-19 infection. The study will include a total of 110 volunteers between the age of 18-60 (ClinicaltrialsNCT04564716, 2020n). Furthermore, the UAE and Venezuela had started phase III trial to determine the safety, immunogenicity, and efficacy of this vaccine candidate (ClinicaltrialsNCT04642339, 2020u; ClinicaltrialsNCT04656613, 2020v).

\section{Ad26.COV2-S}

Janssen Pharmaceutical Companies has nominated their main vaccine candidate recombinant Ad26.COV2-S (Ad26COVS1/ JNJ-78436,735) for prophylaxis of COVID-19 infection. A phase I/IIa, placebo-controlled, randomized, double-blind trial is in progress since July 15,2020 , with the aim of assessing safety, immunogenicity, and reactogenicity of Ad26.COV2-S against SARS-CoV-2 in healthy adults (18-55 years old) (ClinicaltrialsNCT04436276, 2020a). On July 30, 2020, a study report published in Nature confirmed that a single dose of Ad26.COV2-S provoked robust neutralizing antibody titers, fruitfully averting subsequent infections and provided widerange protection against SARS-CoV-2 in both the upper and lower respiratory tract of rhesus macaques (Mercado et al., 2020). Another study published on September 3, 2020, established that a single dose of Ad26.COV2-S can protect hamsters against the clinical conditions resulting after a high-dose intranasal challenge of SARS-CoV-2; it also elicited binding and neutralizing antibody response (Tostanoski et al., 2020). To evaluate the safety and efficacy of Ad26.COV2-S, a large-scale, randomized, pivotal, double-blind, multicentric, placebo-controlled phase III trial (ENSEMBLE) has been launched by the developer companies, which will enroll up to 60,000 volunteers across three continents (ClinicaltrialsNCT04505722, 2020d). A non-peer-reviewed research report established that a single immunization of Ad26.COV2-S is safe and immunogenic against SARS-CoV-2 (Sadoff et al., 2020). Nevertheless, recently ENSEMBLE-2, another phase III trial has been started for the efficacy and safety assessment of the vaccine (ClinicaltrialsNCT04614948, 2020t).

Phase I clinical trials are in progress for five more nonreplicating viral vector-based vaccine candidates.

The Ad5-S-Fusion + N-ETSD is a vaccine candidate sponsored by ImmunityBio, Inc., which is a bivalent human adenovirus serotype 5 (hAd5) vector with E1/E2b/E3 omissions and expressing spike glycoprotein of SARS-CoV-2 and a conserved nucleocapsid $(\mathrm{N})$ with an improved T-cell stimulation domain. This vaccine candidate was suggested to be optimized for immunogenicity, as per a preclinical study report, because the S-fusion shows enhanced $S$ receptor-binding domain (RBD) cell surface expression, which reserved conformational integrity and identification by ACE2-Fc. The N-ETSD protein is restricted to lysosomal/endosomal subcellular compartments for MHC I/II presentation. Refinements on S-Fusion and N-ETSD had enhanced de novo humoral and cellular immune response in antigen-naive preclinical models (Rice et al., 2020). Based on preclinical 
indications, ImmunityBio, Inc. has started a phase Ib, open-label study in healthy adults, where safety, immunogenicity, and reactogenicity of the vaccine candidate will the assessed (ClinicaltrialsNCT04591717, 2020r). Moreover, an open-label, phase Ib trial has been designed in South Africa to confirm the safety profile and to determine a proper dose of the vaccine for further studies (ClinicaltrialsNCT04710303).

The GRAd-COV2 is a vaccine candidate against COVID-19 pandemic based on a novel replication-incompetent simian adenovirus strain expressing the full-length $S$ glycoprotein of SARA-CoV-2, which is being developed by ReiThera, an Italian-based biotech company. Simian adenoviral vectors represent an extensively used vaccine against many emerging infectious diseases because of their excellent safety profile, advanced manufacturing methods, and rapid onset of cellular and humoral immune responses (covidX, 2020). A phase I, dose escalation open-label, multicenter clinical trial (RT-CoV-2) is ongoing to determine the safety and immunogenicity of GRAdCOV2 against SARS-CoV-2 (ClinicaltrialsNCT04528641, 2020g).

One more recombinant adenovirus type 5 vector vaccine, namely, $\mathrm{Ad} 5-\mathrm{nCoV}$ is in phase I clinical trial sponsored by the Institute of Biotechnology, Academy of Military Medical Sciences, PLA of China. The study will perform safety and immunogenicity assessment of two doses of Ad5-nCoV followed by mucosal and intramuscular vaccination in different administration schedules (ClinicaltrialsNCT04552366, 2020k). The VXA-CoV2-1 is an oral recombinant adenoviral-vector based vaccine expressing an antigen of SARS-CoV-2 and dsRNA adjuvant. VXA-CoV2-1 is formulated by Vaxart (an American biotech. Company), as an enterically coated tablet. The vaccines target the small bowel, thus engaging the finely tuned immune system of the gut to produce broad, persistent systemic and mucosal immune response (NCT04563702; VAXART, 2020). Vaxart has designed an open-label, dose-ranging phase I clinical study for safety and immunogenicity assessment of two doses of VXA-CoV-1 against SARS-CoV-2 in healthy adult subjects (aged 18-54 years) (ClinicaltrialsNCT04563702, 2020m). MVA-SARS-2-S is another promising COVID-19 vaccine candidate, which comprises a modified vaccinia virus Ankara (MVA) vector-expressing S protein of SARS-CoV-2. Recombinant MVA vector has revealed promising results in MERS-CoV vaccine development (Koch et al., 2020). Depending on this, two MVA-based vaccines MVA/S (express a prefusion state stabilized, membrane-anchored full-length S protein) and MVA/S1 (express the S1 region of the spike which forms trimers) had developed during COVID19 pandemic, and a preclinical study on the mouse model had demonstrated MVA/S as a promising vaccine candidate against SARS-CoV-2 (Routhu et al., 2020). To determine the safety, tolerability, and immunogenicity of MVA-SARS$2-S$, an open, single-center phase I trial has been developed by University Medical Center Hamburg-Eppendorf. The study includes healthy subjects in two different dose cohorts and vaccinated twice with the proposed vaccine candidate (ClinicaltrialsNCT04569383, 20200).
Alongside nonreplicating viral vector-based vaccine candidates, replicating viral vector-based vaccine candidates are also in headway.

The vaccine candidate DELNS1-2019-nCoV-RBD-OPT1 is established on flu-based DelNS1 live-attenuated influenza virus (LAIV) platform from which immune antagonist (NS1) and the key virulent element has been deleted and encoded with SARSCoV-2's S protein. DELNS1-2019-nCoV-RBD-OPT1 has been developed as an intranasal spray and is being evaluated in China for its safety and immunogenicity (ChiCTR2000037782, 2020). Recently, a phase II clinical trial has been started for this vaccine candidate (ChiCTR2000039715, 2020).

Israel Institute of Biological Research (IIBR) has developed a replication-competent vesicular stomatitis virus (VSV) vaccine candidate, encoding $\mathrm{S}$ protein of SARS-CoV-2 (rVSV-SARS$\mathrm{CoV}-2-\mathrm{S}$ ). Preclinical investigation revealed that, rVSV-SARS$\mathrm{CoV}-2-\mathrm{S}$ resembles the SARS-CoV-2, in antigenicity, spike expression properties, and neutralizing antibody production ability. Furthermore, single-dose immunization with the vaccine candidate, proved to be safe, effective, and elicited sufficient neutralizing antibody against SARS-CoV-2 infection (Yahalom-Ronen et al., 2020). Another study by Li et al., 2020b concluded that rVSVs holds excellent potential for studying SASR-CoV-2 host interactions, immune response characterization, and neutralizing antibodies detection and can be a promising vaccine candidate for prophylaxis of COVID-19 (H. Li et al., 2020). Additionally, Dieterle et al., 2020 reported that, in high-throughput fluorescent reporter assay, the neutralization properties of a huge panel convalescent sera of COVID-19 can be evaluated with rVSV-SARS-CoV-2S and the antisera neutralization of the rVSV and SARS-CoV-2 is vastly correlated (Dieterle et al., 2020). Considering these results, a phase I clinical trial has been started to evaluate safety, efficacy, and immunogenicity of rVSV-SARS-CoV-2S in healthy adults, and the study has been promoted to phase II on 28th October 2020 (ClinicaltrialsNCT04608305, 2020s).

Another vaccine candidate, V590 is a recombinant vesicular stomatitis virus (rVSV) developed by Merck and Co., which is repurposed from Merck's Ebola Zaire virus vaccine (GEN, 2020). A phase I study has begun with the hypothesis that as determined by plaque reduction neutralization test, so far, a possible one welltolerated dose of V590 raises the geometric mean titers of COVID-19 anti-serum neutralizing antibody when compared to placebo (ClinicaltrialsNCT04569786, 2020p). Furthermore, a phase I randomized, placebo-controlled, two center trial on a novel measles vector-based vaccine candidate, developed by Institut Pasteur, is in progress to determine its safety, tolerability, and immunogenicity against SARS-CoV-2 (ClinicaltrialsNCT04497298, 2020b). Furthermore, a phase I/phase II trial has been started with the objective to identify the dose range in order to reach targeted immunogenicity (ClinicaltrialsNCT04498247, 2020c). An intranasal adenovirus type 5 (Ad5) vector vaccine candidate (AdCOVID) expressing the $\mathrm{RBD}$ of the $\mathrm{S}$ protein of SARS-CoV-2, had shown a potent immune response against $\mathrm{RBD}$ via the generation of serum neutralizing antibodies, mucosal $\operatorname{IgA}$ induction, and expression of $\mathrm{CD}^{+}$and $\mathrm{CD}^{+}$T-cells with a Th-1-like 
TABLE 2 | List of viral vector-based vaccine candidates under preclinical evaluation (WHO, 2021).

Developer/manufacturer

Nonreplicating viral vector-based vaccine candidates

University of Helsinki/University of Eastern Finland

Theravectys-Institut Pasteur

ID Pharma

Ankara University

Massachusetts General Hospital/AveXis

GeoVax/BravoVax

DZIF- German Center for Infection Research/DT Biologika GmbH

IDIBAPS-Hospital Clinic (Spain)

AIOVA

Erciyes University

Greffex

Stabilitech Biopharma Ltd

Valo Therapeutics Ltd

Centro Nacional Biotecnologia (CNB-CSIC) (Spain)

University of Georgia/University of Lowa

Bharat Biotech/Thomas Jefferson University

National Research Center (Egypt)

Icahn School of Medicine at Mount Sinai

Vaxart

Sorbonne University

Replicating viral vector-based vaccine candidates

Farmacologicos Veterinarios SAC (FARVET SAC)/Universidad Peruana Cayetano Heredia

(UPCH)

KU Leuven

Cadila Healthcare Limited

FBRI SRS VB VECTOR, Rospotrebnadzor, Koltsovo

CanVirex AG/DZIF- German Center for Infection Research

Tonix Pharma/Southern Research

BiOCAD/IEM

FBRI SRC VB VECTOR, rospotrebnadzor, Koltsovo

Instituto Buntantan/Fundacao Oswaldo Cruz

University of Hong Kong

University of Manitoba

University of Western Ontario

Aurobindo

FBRI SRC VB VECTOR, Rospotrebnadzor, Koltsovo

UW-Madison, Bharat Biotech and FluGen

Intravacc, Utrecht University, Wageningen Bioveterinary Research

The Lancaster University (United Kingdom)

Farvet SAC

Farvet SAC
Type of vaccine candidate

\author{
Ad 5 vector \\ Lentiviral vector \\ Sendai virus vector \\ Adenovirus-based \\ AAVCOVID \\ MVA-encoded VLP \\ MVA-S encoded \\ MVA-S \\ Lentiviral vector \\ Adeno5-based \\ Ad5 S \\ Oral Ad5 S \\ Adenovirus-based + HLA-matched peptides \\ MVA expressing structural proteins \\ PIV5 \\ Recombinant deactivated rabies virus containing S1 \\ Influenza a H1N1 vector \\ Newcastle disease virus expressing $S$ \\ Oral vaccine platform \\ Lentiviral vector Retro-VLP particles \\ rNDV-FARVET expressing RBD \\ YF17D vector \\ Measles vector \\ Measles vector \\ Measles virus (S, N targets) \\ Horsepox vector expressing $S$ protein \\ Attenuated influenza virus based live viral vectored vaccine \\ Influenza-based recombinant vaccine \\ Attenuated influenza expressing an antigenic portion of the spike protein \\ Influenza vector expressing RBD \\ Replicating VSV vector-based DC-targeting \\ VSV-S \\ VSV-S \\ VSV vector \\ M2SR influenza vector \\ NDV-SARS-CoV-2/Spike \\ APMV \\ rNDV-LS1-HN-RBD/SARS-CoV-2 \\ rNDV-LS1-S1-F/SARS-CoV-2
}

cytokine (King et al., 2020). A phase I trial has been designed by Altimmune to assess the safety and immunogenicity of AdCOVID (ClinicaltrialsNCT04679909, 2020w).

Accompanying the clinical trials, 39 preclinical studies on viral vector-based COVID-19 vaccine are in progress and are showing promising results. Table 2 summarizes the list of viral vector-based COVID-19 vaccine candidates undergoing preclinical evaluation (WHO, 2021).

\section{CONCLUSION AND FUTURE PROSPECTIVE}

The outbreaks of SARS in 2002, MERS in 2012, and COVID-19 in 2019 show that there has been a new major CoV outbreak in every decade of the 21 st century so far. Thus, it can be expected that such epidemics can emerge in the future. However, in order to contain the prevailing scenario of COVID-19, rapid development of a safe, reliable, and potent vaccine is urgently needed. An ideal vaccine should have the ability to generate excellent immunogenic response (irrespective of age) with low antigen dosage against different viral strains of the same pathogen with no adverse effects. Although several attempts have been made in order to generate a successful vaccine candidate for the prophylaxis of SARS-CoV-2, till date, no approved vaccine is available. The foremost challenge while developing a vaccine against newly emerging virus is to find out various properties of the virus such as mode of entry, target organ, genomic sequence, mechanism of action, mutation, development of immunity, symptomatic and asymptomatic nature, and relapse of the infection. Similarly, while using viral vectors as platform for vaccine development, it is necessary to identify the genotoxicity, 
epidemiology, and virology of pathogenic as well as viral vector viruses. Thus, for the newly emergent viruses like SARS-CoV-2, rapid production of a viral vector-based vaccine is difficult. Moreover, delay of the real anticipated immune response to the pathogenic virus is also a significant restriction in case of viral vector-based vaccine candidates, because preexisting immune response is primarily acquired due to the vector virus.

Importantly, common challenges with all COVID-19 vaccine platforms include unavailability of the adequate preclinical model and establishment of a proper administration route. Selection of the animal model for preclinical testing of vaccine itself is associated with several challenges such as presence of the natural immunity against SARS-CoV-2, absence of ACE2 receptor, and unanticipated pathogenicity or immunogenicity against the testing virus.

Nevertheless, another major issue, particularly, in manufacturing of vaccine candidate is the bioprocessing scaleup of the vaccine with the highly pure antigen. Currently all the experiments on vaccine candidates are achieved by small-scale production of antigen in the laboratory; however, in the race for rapid production of vaccine, large-scale production might be hampered by the purity of the antigen product. Thus, safety and immunogenicity of the vaccine candidate may be altered and may lead to some untoward adverse effects.

Though there are many challenges associated with the production of vaccine against COVID-19 infection, with a growing number of research studies progressing toward the later stage of clinical trials, there is tremendous enthusiasm and optimism in the area of viral vector-based vaccine development against the pandemic. For instance, ChAdOx-S is showing an excellent potential as a promising COVID-19 vaccine candidate, 2020. On September 6, 2020, AstraZeneca, the ChAdOx-S developing company, had paused the trials after a woman participant showed some neurological symptoms related to transverse myelitis. However, the trial resumed in 2020, after confirming the safety of the vaccine candidate by the UK's Medicines Health Regulatory Authority

\section{REFERENCES}

Ashour, H. M., Elkhatib, W. F., Rahman, M. M., and Elshabrawy, H. A. (2020). Insights into the recent 2019 novel coronavirus (SARS-CoV-2) in light of past human coronavirus outbreaks. Pathogens 9, 186. doi:10.3390/ pathogens 9030186

Awadasseid, A., Wu, Y., Tanaka, Y., and Zhang, W. (2021). Current advances in the development of SARS-CoV-2 vaccines. Int. J. Biol. Sci. 17, 8. doi:10.7150/ijbs.52569

Badgujar, K. C., Badgujar, V. C., and Badgujar, S. B. (2020). Vaccine development against coronavirus (2003 to present): an overview, recent advances, current scenario, opportunities and challenges. Diabetes Metab. Syndr. 14, 1361-1376. doi:10.1016/j.dsx.2020.07.022

Bliss, C. M., Bowyer, G., Anagnostou, N. A., Havelock, T., Snudden, C. M., Davies, $\mathrm{H}$., et al. (2018). Assessment of novel vaccination regimens using viral vectored liver stage malaria vaccines encoding ME-TRAP. Sci. Rep. 8, 3390. doi:10.1038/ s41598-018-21630-4

Bodmer, B. S., Fiedler, A. H., Hanauer, J. R. H., Prüfer, S., and Mühlebach, M. D. (2018). Live-attenuated bivalent measles virus-derived vaccines targeting Middle East respiratory syndrome coronavirus induce robust and multifunctional $\mathrm{T}$ cell responses against both viruses in an appropriate mouse model. Virology 521, 99-107. doi:10.1016/j.virol.2018.05.028
(Live Science, 2020; STAT, 2020). The U.S. Department of Health and Human Services (HHS) had announced up to \$1.2 billion to AstraZeneca for rapid development of the vaccine and to manufacture at least 300 million doses, after assessment of safety and efficacy of the vaccine candidate (Division, 2020). Furthermore, Johnson \& Johnson had an agreement of \$1 billion, with the U.S. government to deliver 100 million doses of the vaccine Ad26.COV2.S in the U.S., following its approval or authorization for emergency use from the U.S. FDA (Johnson and Johnson, 2020). Therefore, considering the preclinical and clinical progress of viral vector-based vaccine candidates in the race of rapid vaccine development, it can be assumed that till the end of this year, a safe and effective viral vector-based vaccine will be available to curtail the COVID-19 pandemic. However, various international funding agencies should mobilize and come forward to promote the vaccine development program by overcoming various challenges and for stockpiling of COVID-19 vaccine.

\section{AUTHOR CONTRIBUTIONS}

RB: conceptualization and original draft preparation. PB: conceptualization and reviewing and editing. BK: supervision and reviewing and editing. NA-S: supervision and reviewing and editing. BC, DJ, MA-Z, and SA-R: reviewing and editing.

\section{ACKNOWLEDGMENTS}

The authors acknowledge Dr. Pran Kishore Deb, Department of Pharmaceutical Sciences, Faculty of Pharmacy, Philadelphia University, Jordan, for his encouragement and valuable suggestions. RB also acknowledges the Department of Pharmaceutical Sciences, Faculty of Science and Engineering, Dibrugarh University, for providing necessary research facilities.

Borah, P., Deb, P. K., Al-Shar'I, N., Dahabiyeh, L., Venugopala, K. N., Singh, V., et al. (2021a). Perspectives on RNA vaccine candidates for COVID-19. Front. Mol. Biosci. 8, 30. doi:10.2139/ssrn.3564664

Borah, P., Deb, P. K., Chandrasekaran, B., Goyal, M., Bansal, M., Hussain, S., et al. (2021b). Neurological consequences of SARS-CoV-2 infection and concurrence of treatment-induced neuropsychiatric adverse events in COVID-19 patients: navigating the uncharted. Front. Mol. Biosci. 8, 27. doi:10.3389/fmolb.2021.627723

Borah, P., Deb, P. K., Deka, S., Venugopala, K. N., Singh, V., Mailavaram, R. P., et al. (2020). Current scenario and future prospect in the management of COVID-19. Curr. Med. Chem. 28 (2), 284-307. doi:10.2174/ 0929867327666200908113642

Bouard, D., Alazard-Dany, D., and Cosset, F. L. (2009). Viral vectors: from virology to transgene expression. Br. J. Pharmacol. 157, 153-165. doi:10.1038/bjp.2008.349

Buchbinder, S. P., McElrath, M. J., Dieffenbach, C., and Corey, L. (2020). Use of adenovirus type-5 vectored vaccines: a cautionary tale. The Lancet 396, e68-e69. doi:10.1016/s0140-6736(20)32156-5

Cai, X., Bai, H., and Zhang, X. (2020). Vaccines and advanced vaccines: A landscape for advanced vaccine technology against infectious disease. COVID-19 Tumor 12, 39. doi:10.31219/osf.io/ypgx4

Candidate-Vaccines. (2020). Draft landscape of COVID-19. Available at: https:// www.who.int/publications/m/item/draft-landscape-of-covid-19-candidate-vaccines (Accessed November 1, 2020). 
Carlos, W. G., Dela Cruz, C. S., Cao, B., Pasnick, S., and Jamil, S. (2020). COVID-19 disease due to SARS-CoV-2 (novel coronavirus). Am. J. Respir. Crit. Care Med. 201, P7-P8. doi:10.1164/rccm.2014p7

CDC. (2019). History of smallpox|smallpox|CDC. Available at: https://www.cdc. gov/smallpox/history/history.html (Accessed October 24, 2020).

CDC. (2020). Prevention and vaccine | Ebola (Ebola virus disease) $\mid$ CDC. Available at: https://www.cdc.gov/vhf/ebola/prevention/index.html (Accessed October $31,2020)$.

CEPI. (2020). CEPI partners with AstraZeneca to manufacture 300 million globally accessible doses of COVID-19 vaccine. CEPI. Available at: https:/cepi.net/news_ cepi/cepi-partners-with-astrazeneca-to-manufacture-300-million-globallyaccessible-doses-of-covid-19-vaccine/ (Accessed November 1, 2020).

Chen, W.-H., Strych, U., Hotez, P. J., and Bottazzi, M. E. (2020). The SARS-CoV-2 vaccine pipeline: an overview. Curr. Trop. Med. Rep. 7, 61-64. doi:10.1007/ s40475-020-00201-6

ChiCTR2000037782. (2020). Chinese Clinical Trial Register (ChiCTR)-the World Health Organization international clinical trials registered organization registered platform. Available at: http://www.chictr.org.cn/ showprojen.aspx?proj=55421 (Accessed November 3, 2020).

ChiCTR2000039715. (2020). Chinese Clinical Trial Register (ChiCTR)-the World Health Organization international clinical trials registered organization registered platform. Available at: http://www.chictr.org.cn/ showprojen.aspx?proj=63754 (Accessed November 19, 2020).

Clinicaltrials. (2020). CTRI/2020/08/027170 ctri. Available at: https://ctri.nic.in/ Clinicaltrials/showallp.php? $\operatorname{mid} 1=46186 \&$ EncHid $=\&$ userName $=$ covid $-19 \%$ 20vaccine (Accessed November 1, 2020).

Clinicaltrials. (2018a). NCT03399578 Safety and immunogenicity of a candidate MERS-CoV vaccine (MERS001) - No study results posted-ClinicalTrials.gov. Available at: https://clinicaltrials.gov/ct2/show/results/NCT03399578 (Accessed October 31, 2020).

Clinicaltrials. (2018b). NCT03615911 Safety, tolerability and immunogenicity of vaccine candidate MVA-MERS-S-full text view-ClinicalTrials.gov. Available at: https://clinicaltrials.gov/ct2/show/NCT03615911 (Accessed October 31, 2020).

Clinicaltrials. (2019). NCT04130594 Double-blind, placebo-controlled study with an open dose selection period for assessing the safety and immunogenicity of the drug "BVRS-GamVac", a vector vaccine for the prevention of the Middle East respiratory syndrome, lyophilisate for the preparation of a solution for intramuscular administration, with the participation of healthy volunteers. Available at: https://clinicaltrials.gov/ct2/show/NCT04130594 (Accessed November 17, 2020).

Clinicaltrials. (2020a). NCT04436276 A randomized, double-blind, placebocontrolled phase $1 / 2 \mathrm{a}$ study to evaluate the safety, reactogenicity, and immunogenicity of Ad26COVS1 in adults aged 18 to 55 years inclusive and adults aged 65 years and older. Available at: https://clinicaltrials.gov/ct2/show/ NCT04436276 (Accessed October 29, 2020).

Clinicaltrials. (2020b). NCT04497298 A randomized, placebo-controlled trial, to evaluate the safety and immunogenicity of the COVID-19 vaccine, a measles vector-based vaccine candidate against COVID-19 in healthy volunteers consisting of an unblinded dose escalation and a blinded treatment phase. Available at: https://clinicaltrials.gov/ct2/show/NCT04497298 (Accessed January 25, 2021).

Clinicaltrials. (2020c). NCT04498247 A phase 1/phase 2, randomized, doubleblind, placebo-controlled, dose-ranging trial to evaluate the safety, tolerability and immunogenicity of V591 (COVID-19 vaccine) in healthy younger and older participants. Available at: https://clinicaltrials.gov/ct2/show/ NCT04498247 (Accessed January 25, 2021).

Clinicaltrials. (2020d). NCT04505722 A randomized, double-blind, placebocontrolled phase 3 study to assess the efficacy and safety of Ad26.COV2.S for the prevention of SARS-CoV-2-mediated COVID-19 in adults aged 18 years and older. Available at: https://clinicaltrials.gov/ct2/show/NCT04505722 (Accessed October 29, 2020).

Clinicaltrials. (2020e). NCT04516746 Phase III double-blind, placebo-controlled study of AZD1222 for the prevention of COVID-19 in adults-full text view-ClinicalTrials.gov. Available at: https://clinicaltrials.gov/ct2/show/ NCT04516746 (Accessed November 19, 2020).

Clinicaltrials. 2020f). NCT04526990 Phase III trial of A COVID-19 vaccine of adenovirus vector in adults 18 years old and above-full text
view-ClinicalTrials.gov. Available at: https://clinicaltrials.gov/ct2/show/ NCT04526990 (Accessed November 1, 2020).

Clinicaltrials. (2020g). NCT04528641 GRAd-COV2 vaccine against COVID19-full text view-ClinicalTrials.gov. Available at: https://clinicaltrials.gov/ ct2/show/NCT04528641 (Accessed November 2, 2020).

Clinicaltrials. (2020h). NCT04530396 Clinical trial of efficacy, safety, and immunogenicity of gam-COVID-vac vaccine against COVID-19-full text view-ClinicalTrials.gov. Available at: https:/clinicaltrials.gov/ct2/show/ NCT04530396 (Accessed November 2, 2020).

Clinicaltrials. (2020i). NCT04540393 AZD1222 vaccine for the prevention of COVID-19-full text view-ClinicalTrials.gov. Available at:https:// clinicaltrials.gov/ct2/show/NCT04540393 (Accessed November 1, 2020).

Clinicaltrials. (2020j). NCT04540419 Clinical trial of recombinant novel coronavirus vaccine (adenovirus type 5 vector) against COVID-19-full text view-ClinicalTrials.gov. Available at: https:/clinicaltrials.gov/ct2/show/ NCT04540419 (Accessed November 1, 2020).

Clinicaltrials. (2020k). NCT04552366 A clinical trial of a recombinant adenovirus 5 vectored COVID-19 vaccine (Ad5-nCoV) with two doses in healthy adults-full text view-ClinicalTrials.gov. Available at: https://clinicaltrials. gov/ct2/show/NCT04552366 (Accessed November 2, 2020).

Clinicaltrials. (2020). NCT04556526 A study of a 2-dose Ebola vaccine regimen of Ad26.ZEBOV followed by MVA-BN-filo in healthy pregnant women-full text view-ClinicalTrials.gov. Available at: https:/clinicaltrials.gov/ct2/show/ NCT04556526 (Accessed November 16, 2020).

Clinicaltrials. (2020m). NCT04563702 A phase 1 open-label, dose-ranging trial to determine the safety and immunogenicity of an adenoviral-vector based vaccine (VXA-CoV2-1) expressing a SARS-CoV-2 antigen and dsRNA adjuvant administered orally to healthy adult volunteers. Available at: https:// clinicaltrials.gov/ct2/show/NCT04563702 (Accessed October 29, 2020).

Clinicaltrials. (2020n). NCT04564716 Clinical trial of efficacy, safety, and immunogenicity of gam-COVID-vac vaccine against COVID-19 in Belarus-full text view-ClinicalTrials.gov. Available at: https://clinicaltrials. gov/ct2/show/NCT04564716 (Accessed November 2, 2020).

Clinicaltrials. (2020o). NCT04569383 Safety, tolerability and immunogenicity of the candidate vaccine MVA-SARS-2-S against COVID-19-full text view-ClinicalTrials.gov. Available at: https:/clinicaltrials.gov/ct2/show/ NCT04569383 (Accessed November 2, 2020).

Clinicaltrials. (2020p). NCT04569786 A phase 1, randomized, double-blind, placebo-controlled, dose-ranging trial to evaluate the safety and immunogenicity of V590 in healthy adults. Available at: https://clinicaltrials. gov/ct2/show/NCT04569786 (Accessed November 2, 2020).

Clinicaltrials. (2020q). NCT04587219 An open study of the safety, tolerability and immunogenicity of the "gam-COVID-Vac"Vaccine against COVID-19 (solution for intramuscular injection) with the participation of volunteers in the age group over 60 years. Available at: https:/clinicaltrials.gov/ct2/show/ NCT04587219 (Accessed October 29, 2020)

Clinicaltrials. (2020r). NCT04591717 Phase 1b open-label study of the safety reactogenicity, and immunogenicity of prophylactic vaccination with 2 nd generation E1/E2B/E3-deleted adenoviral-COVID-19 in normal healthy volunteers. Available at: https://clinicaltrials.gov/ct2/show/NCT04591717 (Accessed October 29, 2020).

Clinicaltrials. (2020s). NCT04608305 Evaluate the safety, immunogenicity and potential efficacy of an rVSV-SARS-CoV-2-S vaccine-full text view-ClinicalTrials.gov. Available at: https:/clinicaltrials.gov/ct2/show/ NCT04608305 (Accessed November 3, 2020).

Clinicaltrials. (2020t). NCT04614948 A randomized, double-blind, placebocontrolled phase 3 study to assess the efficacy and safety of Ad26.COV2.S for the prevention of SARS-CoV-2-mediated COVID-19 in adults aged 18 years and older. Available at: https://clinicaltrials.gov/ct2/show/NCT04614948 (Accessed November 18, 2020).

Clinicaltrials. (2020u). NCT04642339 Randomized, double-blind, placebo controlled, clinical trial of the immunogenicity, safety, and efficacy of the gam-COVID-vac combined vector vaccine in prophylactic treatment for SARS-CoV-2 infection. Available at: https:/clinicaltrials.gov/ct2/show/ NCT04642339 (Accessed January 25, 2021).

Clinicaltrials. (2020v). NCT04656613 A phase III, randomized, double -blind, placebocontrolled trial to evaluate immunogenicity and safety of the gam-COVID-vac combined vector vaccine in prophylactic treatment for SARS-CoV-2 infection in 
the United Arab Emirates. clinicaltrials.gov. Available at: https://clinicaltrials.gov/ ct2/show/NCT04656613 (Accessed January 25, 2021).

Clinicaltrials. (2020). NCT04679909 A phase 1, double-blind, randomized, placebo-controlled, first-in-human study of the safety and immunogenicity of AdCOVID administered as one or two doses. Available at: https:// clinicaltrials.gov/ct2/show/NCT04679909 (Accessed January 26, 2021).

Clinicaltrials. (2021). NCT04710303 Phase 1b open-label study of the safety, reactogenicity, and immunogenicity of a city of a prophylactiv COVID-19 vaccination using a 2nd generation E1/E2B/E3-Deleted adenoviral platform in healthy South African adults (ProVIVA-SA-1). Available at: https:// clinicaltrials.gov/ct2/show/NCT04710303 (Accessed January 25, 2021).

Commissioner, O. (2020). Of the first FDA-approved vaccine for the prevention of Ebola virus disease, marking a critical milestone in public health preparedness and response. Available at: https://www.fda.gov/news-events/pressannouncements/first-fda-approved-vaccine-prevention-ebola-virus-diseasemarking-critical-milestone-public-health Accessed September 30, 2020).

Cooney, E. L., Collier, A. C., Greenberg, P. D., Coombs, R. W., Zarling, J., Arditti, D. E., et al. (1991). Safety of and immunological response to a recombinant vaccinia virus vaccine expressing HIV envelope glycoprotein. Lancet 337, 567-572. doi:10.1016/0140-6736(91)91636-9

Corman, V. M., Muth, D., Niemeyer, D., and Drosten, C. (2018). Hosts and sources of endemic human coronavirusesAdv virus resin. Adv. Virus Res. 100, 163-188. doi:10.1016/bs.aivir.2018.01.001

Coronavirus COVID-19. (2020). Natl. Inst. Health NIH. Available at: https://www. nih.gov/coronavirus Accessed September 29, 2020).

Coutard, B., Valle, C., de Lamballerie, X., Canard, B., Seidah, N. G., and Decroly, E. (2020). The spike glycoprotein of the new coronavirus 2019-nCoV contains a furin-like cleavage site absent in $\mathrm{CoV}$ of the same clade. Antivir. Res. 176, 104742. doi:10.1016/j.antiviral.2020.104742

covidX. (2020). GRAd-COV2. Available at: https://www.covidx.eu/grad-cov2 Accessed September 21, 2020).

Creative Biolabs. (2021). Viral vector vaccine design - creative Biolabs. Available at: https://www.creative-biolabs.com/vaccine/viral-vector-vaccine-design.htm (Accessed January 25, 2021).

Crystal, R. G. (2014). Adenovirus: the first effective in vivo gene delivery vector. Hum. Gene Ther. 25, 3-11. doi:10.1089/hum.2013.2527

Cyranoski, D. (2020). This scientist hopes to test coronavirus drugs on animals in locked-down Wuhan. Nature 577, 607. doi:10.1038/d41586-020-00190-6

de Vries, R. D., and Rimmelzwaan, G. F. (2016). Viral vector-based influenza vaccines. Hum. Vaccin. Immunother. 12, 2881-2901. doi:10.1080/21645515. 2016.1210729

DeMaria, P. J., and Bilusic, M. (2001). Cancer vaccines. Hematol. Oncol. Clin. North. Am. 15, 741-773.

Dhama, K., Sharun, K., Tiwari, R., Dadar, M., Malik, Y. S., Singh, K. P., et al. (2020). COVID-19, an emerging coronavirus infection: advances and prospects in designing and developing vaccines, immunotherapeutics, and therapeutics. Hum. Vaccin. Immunother. 16, 1232-1238. doi:10.1080/21645515.2020. 1735227

Dicks, M. D., Spencer, A. J., Edwards, N. J., Wadell, G., Bojang, K., Gilbert, S. C., et al. (2012). A novel chimpanzee adenovirus vector with low human seroprevalence: improved systems for vector derivation and comparative immunogenicity. PLoS One 7, e40385. doi:10.1371/journal.pone.0040385

Dieterle, M. E., Haslwanter, D., Bortz, R. H., III, Wirchnianski, A. S., Lasso, G., Vergnolle, O., et al. (2020). A replication-competent vesicular stomatitis virus for studies of SARS-CoV-2 spike-mediated cell entry and its inhibition. Cell Host Microbe. 28 (3), 486-496. doi:10.1016/j.chom.2020.06.020

Division, N. (2020). Trump administration's operation warp speed accelerates AstraZeneca COVID-19 vaccine. Available at: https://www.hhs.gov/about/ news/2020/05/21/trump-administration-accelerates-astrazeneca-covid-19-vaccineto-be-available-beginning-in-october.html Accessed November 5, 2020).

Ekblad, M., and Halldén, G. (2010). Adenovirus-based therapy for prostate cancer. Curr. Opin. Mol. Ther. 12, 421-431.

EMA (2020). New vaccine for prevention of Ebola virus disease recommended for approval in the European Union | European Medicines Agency. Available at: https://www.ema.europa.eu/en/news/new-vaccine-prevention-ebola-virus-diseaserecommended-approval-european-union Accessed November 15, 2020).

Ertl, H. C. (2016). Viral vectors as vaccine carriers. Curr. Opin. Virol. 21, 1-8. doi:10.1016/j.coviro.2016.06.001
FDA (2019). IMLYGIC (talimogene laherparepvec) | FDA. Available at: https:// www.fda.gov/vaccines-blood-biologics/cellular-gene-therapy-products/imlygictalimogene-laherparepvec Accessed October 30, 2020).

Fenner, F., Henderson, D. A., Arita, I., Jezek, Z., and Ladnyi, I. D. (1988). Smallpox and its eradication. Geneva: World Health Organization.

Folegatti, P. M., Bittaye, M., Flaxman, A., Lopez, F. R., Bellamy, D., Kupke, A., et al. (2020). Safety and immunogenicity of a candidate Middle East respiratory syndrome coronavirus viral-vectored vaccine: a dose-escalation, open-label, non-randomised, uncontrolled, phase 1 trial. Lancet Infect. Dis. 20, 816-826. doi:10.1016/S1473-3099(20)30160-2

Franchini, G., Gurunathan, S., Baglyos, L., Plotkin, S., and Tartaglia, J. (2004). Poxvirus-based vaccine candidates for HIV: two decades of experience with special emphasis on canarypox vectors. Expert Rev. Vaccin. 3, S75-S88. doi:10. 1586/14760584.3.4.s75

Fu, Y. J., Du, J., Yang, R. J., Yin, L. T., and Liang, A. H. (2010). Potential adenovirusmediated gene therapy of glioma cancer. Biotechnol. Lett. 32, 11-18. doi:10. 1007/s10529-009-0132-0

Gen (2020). Merck \& Co. And IAVI-V590. GEN-genet. Eng. Biotechnol. News. Available at: https://www.genengnews.com/covid-19-candidates/merck-coand-iavi/ (Accessed November 3, 2020).

Gómez, C. E., Nájera, J. L., Perdiguero, B., García-Arriaza, J., Sorzano, C. O. S., Jiménez, V., et al. (2011). The HIV/AIDS vaccine candidate MVA-B administered as a single immunogen in humans triggers robust, polyfunctional, and selective effector memory $\mathrm{T}$ cell responses to HIV-1 antigens. J. Virol. 85, 11468-11478. doi:10.1128/JVI.05165-11

Gulley, J. L., Borre, M., Vogelzang, N. J., Ng, S., Agarwal, N., Parker, C. C., et al. (2019). Phase III trial of PROSTVAC in asymptomatic or minimally symptomatic metastatic castration-resistant prostate cancer. J. Clin. Oncol. 37, 1051-1061. doi:10.1200/JCO.18.02031

Guo, C., Manjili, M. H., Subjeck, J. R., Sarkar, D., Fisher, P. B., and Wang, X. Y. (2013). Therapeutic cancer vaccines: past, present, and future. Adv. Cancer Res. 119, 421-475. doi:10.1016/B978-0-12-407190-2.00007-1

Guo, X., Deng, Y., Chen, H., Lan, J., Wang, W., Zou, X., et al. (2015). Systemic and mucosal immunity in mice elicited by a single immunization with human adenovirus type 5 or 41 vector-based vaccines carrying the spike protein of Middle East respiratory syndrome coronavirus. Immunology 145, 476-484. doi:10.1111/imm.12462

Guo, Y. R., Cao, Q. D., Hong, Z. S., Tan, Y. Y., Chen, S. D., Jin, H. J., et al. (2020). The origin, transmission and clinical therapies on coronavirus disease 2019 (COVID-19) outbreak-an update on the status. Mil. Med. Res. 7, 11-10. doi:10.1186/s40779-020-00240-0

Hashem, A. M., Algaissi, A., Agrawal, A. S., Al-Amri, S. S., Alhabbab, R. Y., Sohrab, S. S., et al. (2019). A highly immunogenic, protective, and safe adenovirus-based vaccine expressing Middle East respiratory syndrome coronavirus S1-CD40L fusion protein in a transgenic human dipeptidyl peptidase 4 mouse model. J. Infect. Dis. 220, 1558-1567. doi:10.1093/infdis/jiz137

Humphreys, I. R., and Sebastian, S. (2018). Novel viral vectors in infectious diseases. Immunology 153, 1-9. doi:10.1111/imm.12829

ISRCTN - ISRCTN89951424. (2020) A phase III study to investigate a vaccine against COVID-19. doi:10.1186/ISRCTN89951424

Iwasaki, A., and Yang, Y. (2020). The potential danger of suboptimal antibody responses in COVID-19. Nat. Rev. Immunol. 20 (6), 1-3. doi:10.1038/s41577020-0321-6

Jacobs, B. L., Langland, J. O., Kibler, K. V., Denzler, K. L., White, S. D., Holechek, S. A., et al. (2009). Vaccinia virus vaccines: past, present and future. Antivir. Res. 84, 1-13. doi:10.1016/j.antiviral.2009.06.006

Jenner, E. (1988). An inquiry into the causes and effects of the variolae vaccine. Chall. Epidemiol. 11, 31-32.

Jin, Y., Yang, H., Ji, W., Wu, W., Chen, S., Zhang, W., et al. (2020). Virology, epidemiology, pathogenesis, and control of COVID-19. Viruses 12, 372. doi:10. $3390 / \mathrm{v} 12040372$

Johnson and Johnson. (2020). Johnson \& Johnson announces agreement with U.S Government for 100 million doses of investigational COVID-19 vaccine| Johnson \& Johnson. Content lab US. Available at: https://www.jnj.com/ johnson-johnson-announces-agreement-with-u-s-government-for-100-milliondoses-of-investigational-covid-19-vaccine (Accessed November 5, 2020).

Johnson, P. R., Schnepp, B. C., Connell, M. J., Rohne, D., Robinson, S., Krivulka, G. R., et al. (2005). Novel adeno-associated virus vector vaccine restricts 
replication of simian immunodeficiency virus in macaques. J. Virol. 79, 955-965. doi:10.1128/JVI.79.2.955-965.200510.1128/JVI.79.2.955-965.2005

Kim, E., Okada, K., Kenniston, T., Raj, V. S., AlHajri, M. M., Farag, E. A., et al. (2014). Immunogenicity of an adenoviral-based Middle East respiratory syndrome coronavirus vaccine in $\mathrm{BALB} / \mathrm{c}$ mice. Vaccine 32, 5975-5982. doi:10.1016/j.vaccine.2014.08.058

King, R. G., Silva-Sanchez, A., Peel, J. N., Botta, D., Meza-Perez, S., Allie, S. R., et al. (2020). Single-dose intranasal administration of AdCOVID elicits systemic and mucosal immunity against SARS-CoV-2 in mice. bioRxiv. doi:10.1101/2020.10. 10.331348

Kingstad-Bakke, B., Brewoo, J. N., Mai, le. Q., Kawaoka, Y., and Osorio, J. E. (2012). Effects of route and coadministration of recombinant raccoon poxviruses on immune responses and protection against highly pathogenic avian influenza in mice. Vaccine 30, 6402-6408. doi:10.1016/j.vaccine.2012.08.018

Koch, T., Dahlke, C., Fathi, A., Kupke, A., Krähling, V., Okba, N. M. A., et al. (2020). Safety and immunogenicity of a modified vaccinia virus Ankara vector vaccine candidate for Middle East respiratory syndrome: an open-label, phase 1 trial. Lancet Infect. Dis. 20, 827-838. doi:10.1016/S1473-3099(20)30248-6

Kotta, S., Aldawsari, H. M., Badr-Eldin, S. M., Alhakamy, N. A., Md, S., Nair, A. B., et al. (2020). Combating the pandemic COVID-19: clinical trials, therapies and perspectives. Front. Mol. Biosci. 7, 114. doi:10.3389/fmolb.2020.606393

Kyriakis, C. S., De Vleeschauwer, A., Barbé, F., Bublot, M., and Van Reeth, K. (2009). Safety, immunogenicity and efficacy of poxvirus-based vector vaccines expressing the haemagglutinin gene of a highly pathogenic $\mathrm{H} 5 \mathrm{~N} 1$ avian influenza virus in pigs. Vaccine 27, 2258-2264. doi:10.1016/j.vaccine.2009. 02.006

Lauer, K. B., Borrow, R., and Blanchard, T. J. (2017). Multivalent and multipathogen viral vector vaccines. Clin. Vaccin. Immunol. 24, e00298-16. doi:10.1128/CVI.00298-16

Ledford, H. (2020). Oxford covid-vaccine paper highlights lingering UNKNOWNS. Nature 588. doi:10.1038/d41586-020-03504-w

Lee, C. S., Bishop, E. S., Zhang, R., Yu, X., Farina, E. M., Yan, S., et al. (2017). Adenovirus-mediated gene delivery: potential applications for gene and cellbased therapies in the new era of personalized medicine. Genes Dis. 4, 43-63. doi:10.1016/j.gendis.2017.04.001

Lee, N., Chan, P. K., Ip, M., Wong, E., Ho, J., Ho, C., et al. (2006). Anti-SARS-CoV IgG response in relation to disease severity of severe acute respiratory syndrome. J. Clin. Virol. 35, 179-184. doi:10.1016/j.jcv.2005.07.005

Li, H., Zhao, C., Zhang, Y., Yuan, F., Zhang, Q., Shi, X., et al. (2020). Establishment of replication-competent vesicular stomatitis virus-based recombinant viruses suitable for SARS-CoV-2 entry and neutralization assays. Emerg. Microbes Infect. 9, 2269-2277. doi:10.1080/22221751.2020.1830715

Li, Q., Wu, J., Nie, J., Zhang, L., Hao, H., Liu, S., et al. (2020). The impact of mutations in SARS-CoV-2 spike on viral infectivity and antigenicity. Cell 182, 1284-e9. doi:10.1016/j.cell.2020.07.012

Li, S., Locke, E., Bruder, J., Clarke, D., Doolan, D. L., Havenga, M. J., et al. (2007). Viral vectors for malaria vaccine development. Vaccine 25, 2567-2574. doi:10. 1016/j.vaccine.2006.07.035

Liniger, M., Zuniga, A., and Naim, H. Y. (2007). Use of viral vectors for the development of vaccines. Expert Rev. Vaccin. 6, 255-266. doi:10.1586/ 14760584.6.2.255

Liu, R., Ge, J., Wang, J., Shao, Y., Zhang, H., Wang, J., et al. (2017). Newcastle disease virus-based MERS-CoV candidate vaccine elicits high-level and lasting neutralizing antibodies in Bactrian camels. J. Integr. Agric. 16, 2264-2273. doi:10.1016/S2095-3119(17)61660-5

Live Science (2020). Here are the most promising coronavirus vaccine candidates out there|Live Science. Available at: https://www.livescience.com/mostpromising-coronavirus-vaccine-candidates.html Accessed November 5, 2020).

Loessner, H., Schwantes, A., Hamdorf, M., Komor, U., Leschner, S., and Weiss, S. (2012). Employing live microbes for vaccine delivery," in Development of Novel Vaccines. Berlin: Springer, 87-124. doi:10.1007\%2F978-3-7091-0709-6_5

Logunov, D. Y., Dolzhikova, I. V., Zubkova, O. V., Tukhvatulin, A. I., Shcheblyakov, D. V., Dzharullaeva, A. S., et al. (2020). Safety and immunogenicity of an $\operatorname{rAd} 26$ and rAd5 vector-based heterologous primeboost COVID-19 vaccine in two formulations: two open, non-randomised phase 1/2 studies from Russia. The Lancet 396, 887-897. doi:10.1016/S01406736(20)31866-3
Lu, R., Zhao, X., Li, J., Niu, P., Yang, B., Wu, H., et al. (2020). Genomic characterisation and epidemiology of 2019 novel coronavirus: implications for virus origins and receptor binding. The Lancet 395, 565-574. doi:10.1016/ s0140-6736(20)30251-8

Lundstrom, K. (2020). Coronavirus pandemic-therapy and vaccines. Biomedicines 8, 109. doi:10.3390/biomedicines 8050109

Lundstrom, K. (2017). Latest trends in cancer therapy applying viral vectors. Future Virol. 12, 667-684. doi:10.2217/fvl-2017-0070

Matthews, K. S., Alvarez, R. D., and Curiel, D. T. (2009). Advancements in adenoviral based virotherapy for ovarian cancer. Adv. Drug Deliv. Rev. 61, 836-841. doi:10.1016/j.addr.2009.04.012

Mayr, A., and Munz, E. (1964). Changes in the vaccinia virus through continuing passages in chick embryo fibroblast cultures. Zentralbl Bakteriol Orig 195, 24.

Medina, R. A., and García-Sastre, A. (2011). Influenza A viruses: new research developments. Nat. Rev. Microbiol. 9, 590-603. doi:10.1038/nrmicro2613

Mercado, N. B., Zahn, R., Wegmann, F., Loos, C., Chandrashekar, A., Yu, J., et al. (2020). Single-shot Ad26 vaccine protects against SARS-CoV-2 in rhesus macaques. Nature 586, 583-588. doi:10.1038/s41586-020-2607-z

Minke, J. M., Toulemonde, C. E., Coupier, H., Guigal, P. M., Dinic, S., Sindle, T., et al. (2007). Efficacy of a canarypox-vectored recombinant vaccine expressing the hemagglutinin gene of equine influenza H3N8 virus in the protection of ponies from viral challenge. Am. J. Vet. Res. 68, 213-219. doi:10.2460/ajvr.68. 2.213

Mura, M., Ruffié, C., Combredet, C., Aliprandini, E., Formaglio, P., Chitnis, C. E., et al. (2019). Recombinant measles vaccine expressing malaria antigens induces long-term memory and protection in mice. Npj Vaccin. 4, 12-18. doi:10.1038/ s41541-019-0106-8

Nakanishi, M., and Otsu, M. (2012). Development of Sendai virus vectors and their potential applications in gene therapy and regenerative medicine. Curr. Gene Ther. 12, 410-416. doi:10.2174/156652312802762518

Norton, T. D., Zhen, A., Tada, T., Kim, J., Kitchen, S., and Landau, N. R. (2019). Lentiviral vector-based dendritic cell vaccine suppresses HIV replication in humanized mice. Mol. Ther. 27, 960-973. doi:10.1016/j. ymthe.2019.03.008

Ockenhouse, C. F., Sun, P., Lanar, D. E., Wellde, B. T., Hall, B. T., Kester, K., et al. (1998). Phase I/IIa safety, immunogenicity, and efficacy trial of NYVAC-Pf7, a pox-vectored, multiantigen, multistage vaccine candidate for Plasmodium falciparum malaria. J. Infect. Dis. 177, 1664-1673. doi:10.1086/515331

Ogwang, C., Kimani, D., Edwards, N. J., Roberts, R., Mwacharo, J., Bowyer, G., et al. (2015). Prime-boost vaccination with chimpanzee adenovirus and modified vaccinia Ankara encoding TRAP provides partial protection against Plasmodium falciparum infection in Kenyan adults. Sci. Transl. Med. 7, 286re5. doi:10.1126/scitranslmed.aaa2373

Ovsyannikova, I. G., Dhiman, N., Jacobson, R. M., Vierkant, R. A., and Poland, G. A. (2003). Frequency of measles virus-specific CD4+ and CD8+ T cells in subjects seronegative or highly seropositive for measles vaccine. Clin. Diagn. Lab. Immunol. 10, 411-416. doi:10.1128/CDLI.10.3.411-416.200310.1128/cdli. 10.3.411-416.2003

Padron-Regalado, E. (2020). Vaccines for SARS-CoV-2: lessons from other coronavirus strains. Infect. Dis. Ther., 9, 1-20. doi:10.1007/s40121-02000300-x

Pantaleo, G., Esteban, M., Jacobs, B., and Tartaglia, J. (2010). Poxvirus vector-based HIV vaccines. Curr. Opin. HIV AIDS 5, 391-396. doi:10.1097/COH. 0b013e32833d1e87

Parrino, J., and Graham, B. S. (2006). Smallpox vaccines: past, present, and future. J. Allergy Clin. Immunol. 118, 1320-1326. doi:10.1016/j.jaci.2006.09.037

Piszczatoski, C. R., and Gums, J. G. (2020). Ervebo (Ebola Zaire vaccine, live/ rVSV $\triangle G-Z E B O V-G P)$ : the first licensed vaccine for the prevention of Ebola virus disease. J. Pharm. Technol. 36.

Precision vaccination. (2020a). Ad5-nCoV COVID-19 vaccine. Available at: https://www.precisionvaccinations.com/vaccines/ad5-ncov-covid-19-vaccine (Accessed September 21, 2020).

Precision vaccination. (2020b). Ad5-nCoV SARS-CoV-2 vaccine. Available at: https://www.precisionvaccinations.com/vaccines/ad5-ncov-sars-cov-2-vaccine (Accessed November 1, 2020).

Precision vaccination. (2020c). AZD1222 SARS-CoV-2 vaccine. Available at: https://www.precisionvaccinations.com/vaccines/azd1222-sars-cov-2-vaccine (Accessed November 1, 2020). 
Ramezanpour, B., Haan, I., Osterhaus, A., and Claassen, E. (2016). Vector-based genetically modified vaccines: exploiting Jenner's legacy. Vaccine 34, 6436-6448. doi:10.1016/j.vaccine.2016.06.059

Ramsauer, K., Schwameis, M., Firbas, C., Müllner, M., Putnak, R. J., Thomas, S. J., et al. (2015). Immunogenicity, safety, and tolerability of a recombinant measlesvirus-based chikungunya vaccine: a randomised, double-blind, placebocontrolled, active-comparator, first-in-man trial. Lancet Infect. Dis. 15, 519-527. doi:10.1016/S1473-3099(15)70043-5

Rauch, S., Jasny, E., Schmidt, K. E., and Petsch, B. (2018). New vaccine technologies to combat outbreak situations. Front. Immunol. 9, 1963. doi:10.3389/fimmu. 2018.01963

Rerks-Ngarm, S., Pitisuttithum, P., Nitayaphan, S., Kaewkungwal, J., Chiu, J., Paris, R., et al. (2009). Vaccination with ALVAC and AIDSVAX to prevent HIV-1 infection in Thailand. N. Engl. J. Med. 361, 2209-2220. doi:10.1056/ NEJMoa0908492

Rice, A., Verma, M., Shin, A., Zakin, L., Sieling, P., Tanaka, S., et al. (2020). A next generation bivalent human Ad5 COVID-19 vaccine delivering both spike and nucleocapsid antigens elicits Th1 dominant CD4+, CD8+ T-cell and neutralizing antibody responses. bioRxiv. doi:10.1101/2020.07.29.227595

Robert-Guroff, M. (2007). Replicating and non-replicating viral vectors for vaccine development. Curr. Opin. Biotechnol. 18, 546-556. doi:10.1016/j.copbio.2007. 10.010

Rogers, S., Lowenthal, A., Terheggen, H. G., and Columbo, J. P. (1973). Induction of arginase activity with the Shope papilloma virus in tissue culture cells from an argininemic patient. J. Exp. Med. 137, 1091. doi:10.1084/jem.137.4.1091

Rollier, C. S., Reyes-Sandoval, A., Cottingham, M. G., Ewer, K., and Hill, A. V. (2011). Viral vectors as vaccine platforms: deployment in sight. Curr. Opin. Immunol. 23, 377-382. doi:10.1016/j.coi.2011.03.006

Romano, G. (2005). Current development of adeno-associated viral vectors. Drug News Perspect. 18, 311. doi:10.1358/dnp.2005.18.5.917326

Ross, A. L., Bråve, A., Scarlatti, G., Manrique, A., and Buonaguro, L. (2010). Progress towards development of an HIV vaccine: report of the AIDS Vaccine 2009 Conference. Lancet Infect. Dis. 10, 305-316. doi:10.1016/S1473-3099(10) 70069-4

Routhu, N. K., Gangadhara, S., Cheedarla, N., Shiferaw, A., Rahman, S. A., Sahoo, A., et al. (2020). Modified vaccinia Ankara based SARS-CoV-2 vaccine expressing full-length spike induces strong neutralizing antibody response. bioRxiv.

Sadoff, J., Le Gars, M., Shukarev, G., Heerwegh, D., Truyers, C., de Groot, A. M., et al. (2020). Safety and immunogenicity of the Ad26.COV2.S COVID-19 vaccine candidate: interim results of a phase $1 / 2 \mathrm{a}$, double-blind, randomized, placebo-controlled trial. medRxiv. doi:10.1101/2020.09.23.20199604

Sauter, S. L., Rahman, A., and Muralidhar, G. (2005). Non-replicating viral vectorbased AIDS vaccines: interplay between viral vectors and the immune system. Curr. HIV Res. 3, 157-181. doi:10.2174/1570162053506900

Schneider, J., Gilbert, S. C., Blanchard, T. J., Hanke, T., Robson, K. J., Hannan, C. M., et al. (1998). Enhanced immunogenicity for CD8+ T cell induction and complete protective efficacy of malaria DNA vaccination by boosting with modified vaccinia virus Ankara. Nat. Med. 4, 397-402. doi:10.1038/ nm0498-397

SelectScience COVID-19 vaccine (2021). Solutions to the complex cold storage paradigm | selectScience. Available at: http://www.selectscience.net/industrynews/covid-19-vaccine-solutions-to-the-complex-cold-storage-paradigm/?

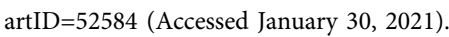

Seymour, L. W., and Fisher, K. D. (2011). Adenovirus: teaching an old dog new tricks. Hum. Gene Ther. 22, 1041-1042. doi:10.1089/hum.2011.2517

Shapira, S., Shapira, A., Kazanov, D., Hevroni, G., Kraus, S., and Arber, N. (2017). Selective eradication of cancer cells by delivery of adenovirus-based toxins. Oncotarget 8, 38581-38591. doi:10.18632/oncotarget.16934

Smith, G. L., Levin, J. Z., Palese, P., and Moss, B. (1987). Synthesis and cellular location of the ten influenza polypeptides individually expressed by recombinant vaccinia viruses. Virology 160, 336-345. doi:10.1016/00426822(87)90004-3

Smith, G. L., Murphy, B. R., and Moss, B. (1983). Construction and characterization of an infectious vaccinia virus recombinant that expresses the influenza hemagglutinin gene and induces resistance to influenza virus infection in hamsters. Proc. Natl. Acad. Sci. USA 80, 7155-7159. doi:10.1073/ pnas.80.23.7155
Song, F., Fux, R., Provacia, L. B., Volz, A., Eickmann, M., Becker, S., et al. (2013). Middle East respiratory syndrome coronavirus spike protein delivered by modified vaccinia virus Ankara efficiently induces virus-neutralizing antibodies. J. Virol. 87, 11950-11954. doi:10.1128/JVI.01672-13

Stat (2020). AstraZeneca Covid-19 vaccine study is put on hold. STAT. Available at: https://www.statnews.com/2020/09/08/astrazeneca-covid-19-vaccine-study-puton-hold-due-to-suspected-adverse-reaction-in-participant-in-the-u-k/ (Accessed November 5, 2020).

Sutter, G., and Staib, C. (2003). Vaccinia vectors as candidate vaccines: the development of modified vaccinia virus Ankara for antigen delivery. Curr. Drug Targets Infect. Disord. 3, 263-271. doi:10.2174/1568005033481123

Tan, W. G., Jin, H. T., West, E. E., Penaloza-MacMaster, P., Wieland, A., Zilliox, M. J., et al. (2013). Comparative analysis of simian immunodeficiency virus gagspecific effector and memory CD8+ T cells induced by different adenovirus vectors. J. Virol. 87, 1359-1372. doi:10.1128/JVI.02055-12

Tangy, F., and Naim, H. Y. (2005). Live attenuated measles vaccine as a potential multivalent pediatric vaccination vector. Viral Immunol. 18, 317-326. doi:10. 1089/vim.2005.18.317

Tapia, M., Sow, S., Lyke, K., Haidara, F., Diallo, F., Doumbia, M., et al. (2015). Use of Chad3-EBO-Z Ebola virus vaccine in Malian and US adults, and boosting of Malian adults with MVA-BN-Filo: a phase 1, single-blind, randomised trial, a phase $1 \mathrm{~b}$, open-label and double-blind, dose-escalation trial, and a nested, randomised, double-blind, placebo-controlled trial. Lancet Infect. Dis. 16, 31. doi:10.1016/S1473-3099(15)00362-X

Taylor, J., Weinberg, R., Kawaoka, Y., Webster, R. G., and Paoletti, E. (1988). Protective immunity against avian influenza induced by a fowlpox virus recombinant. Vaccine 6, 504-508. doi:10.1016/0264-410x(88)90101-6

The Scientist (2020). Vector-based vaccines come to the fore in the COVID-19 pandemic. Sci Mag. Available at: https://www.the-scientist.com/news-opinion/ vector-based-vaccines-come-to-the-fore-in-the-covid-19-pandemic-67915 (Accessed September 21, 2020).

Times Now Digital (2020). Covishield update: Oxford COVID-19 vaccine may be ready by December, says Serum Institute CEO. Available at: https://www. timesnownews.com/health/article/covishield-update-oxford-covid-19-vaccinemay-be-ready-by-december-says-serum-institute-ceo/674790 (Accessed November 1, 2020).

Tiono, A. B., Nébié, I., Anagnostou, N., Coulibaly, A. S., Bowyer, G., Lam, E., et al. (2018). First field efficacy trial of the Chad63 MVA ME-TRAP vectored malaria vaccine candidate in 5-17 months old infants and children. PLoS One 13, e0208328. doi:10.1371/journal.pone.0208328

Tostanoski, L. H., Wegmann, F., Martinot, A. J., Loos, C., McMahan, K., Mercado, N. B., et al. (2020). Ad26 vaccine protects against SARS-CoV-2 severe clinical disease in hamsters. Nat. Med. 26, 1694-1697. doi:10.1038/s41591-020-1070-6 Trial Resumes. (2020). Available at: /trial-resumes (Accessed November 1, 2020)

Tulman, E. R., Delhon, G., Afonso, C. L., Lu, Z., Zsak, L., Sandybaev, N. T., et al. (2006). Genome of horsepox virus. J. Virol. 80, 9244-9258. doi:10.1128/JVI.00945-06

Ura, T., Okuda, K., and Shimada, M. (2014). Developments in viral vector-based vaccines. Vaccines (Basel) 2, 624-641. doi:10.3390/vaccines2030624

Urabe, M., Ding, C., and Kotin, R. M. (2002). Insect cells as a factory to produce adeno-associated virus type 2 vectors. Hum. Gene Ther. 13, 1935-1943. doi:10. 1089/10430340260355347

van Doremalen, N., Lambe, T., Spencer, A., Belij-Rammerstorfer, S., Purushotham, J. N., Port, J. R., et al. (2020). ChAdOx1 nCoV-19 vaccination prevents SARSCoV-2 pneumonia in rhesus macaques. bioRxiv. doi:10.1101\%2F2020.05.13. 093195

van Riel, D., and de Wit, E. (2020). Next-generation vaccine platforms for COVID19. Nat. Mater. 19, 810-812. doi:10.1038/s41563-020-0746-0

Vaxart (2020). Oral vaccines-Vaxart Inc. Available at: https://vaxart.com/tabletvaccines/Accessed November 2, 2020).

Veit, S., Jany, S., Fux, R., Sutter, G., and Volz, A. (2018). CD8+ T cells responding to the middle east respiratory syndrome coronavirus nucleocapsid protein delivered by vaccinia virus MVA in mice. Viruses 10, 718. doi:10.3390/v10120718

Volz, A., Kupke, A., Song, F., Jany, S., Fux, R., Shams-Eldin, H., et al. (2015). Protective efficacy of recombinant modified vaccinia virus Ankara delivering Middle East respiratory syndrome coronavirus spike glycoprotein. J. Virol. 89, 8651-8656. doi:10.1128/JVI.00614-15

Voysey, M., Clemens, S. A. C., Madhi, S. A., Weckx, L. Y., Folegatti, P. M., Aley, P. K., et al. (2021). Safety and efficacy of the ChAdOx1 nCoV-19 vaccine 
(AZD1222) against SARS-CoV-2: an interim analysis of four randomised controlled trials in Brazil, South Africa, and the UK. The Lancet 397, 99-111. doi:10.1016/S0140-6736(20)32661-1

Who (2018). 2_Ebola_SAGE2018Oct_BgDoc_20180919.pdf. Available at: https://www.who.int/immunization/sage/meetings/2018/october/2_Ebola_ SAGE2018Oct_BgDoc_20180919.pdf (Accessed. November 19, 2020).

Who (2020a). Clinical management of COVID-19. Available at: https://www.who. int/publications-detail-redirect/clinical-management-of-covid-19 (Accessed September 29, 2020).

Who (2021). Draft landscape and tracker of COVID-19 candidate vaccines. Available at: https://www.who.int/publications/m/item/draft-landscape-ofcovid-19-candidate-vaccines (Accessed January 24, 2021).

Who (2020b). Draft landscape of COVID-19 candidate vaccines. Available at: https://www.who.int/publications/m/item/draft-landscape-of-covid-19-candidatevaccines (Accessed November 18, 2020).

Who (2020c). Ebola virus disease. Available at: https://www.who.int/news-room/ fact-sheets/detail/ebola-virus-disease (Accessed November 15, 2020).

Who (2020d). HIV/AIDS. Available at: https://www.who.int/news-room/factsheets/detail/hiv-aids (Accessed October 28, 2020).

Who (2020e). List-of-candidate-vaccines-developed-against-sars.pdf. Available at: https://www.who.int/blueprint/priority-diseases/key-action/list-of-candidatevaccines-developed-against-sars.pdf (Accessed October 31, 2020).

WHO (2020f). WHO coronavirus disease (COVID-19) dashboard. Available at: https://covid19.who.int (Accessed November 18, 2020).

Wold, W., and Toth, K. (2013). Adenovirus vectors for gene therapy, vaccination and cancer gene therapy. Curr. Gene Ther. 13, 421-433. doi:10.2174/ 1566523213666131125095046

Xiao, W., Chirmule, N., Berta, S. C., McCullough, B., Gao, G., and Wilson, J. M. (1999). Gene therapy vectors based on adeno-associated virus type 1. J. Virol. 73, 3994-4003. doi:10.1128/JVI.73.5.3994-4003.1999

Yadav, T., Srivastava, N., Mishra, G., Dhama, K., Kumar, S., Puri, B., et al. (2020). Recombinant vaccines for COVID-19. Hum. Vaccin. Immunother. 16, 2905-2912. doi:10.1080/21645515.2020.1820808

Yahalom-Ronen, Y., Tamir, H., Melamed, S., Politi, B., Shifman, O., Achdout, H., et al. (2020). A single dose of recombinant VSV- $\Delta$ G-spike vaccine provides protection against SARS-CoV-2 challenge. bioRxiv. doi:10.1101/2020.06.18. 160655

Yong, C. Y., Ong, H. K., Yeap, S. K., Ho, K. L., and Tan, W. S. (2019). Recent advances in the vaccine development against Middle East respiratory syndrome-coronavirus. Front. Microbiol. 10, 1781. doi:10.3389/fmicb.2019. 01781

Yoo, J.-H. (2019). The fight against the 2019-nCoV outbreak: an arduous march has just begun. J. Korean Med. Sci. 35 .

Yu, F., Du, L., Ojcius, D. M., Pan, C., and Jiang, S. (2020). Measures for diagnosing and treating infections by a novel coronavirus responsible for a pneumonia outbreak originating in Wuhan, China. Microbes Infect. 22, 74-79. doi:10.1016/ j.micinf.2020.01.003

Zhang, C., Zhou, C., Shi, L., and Liu, G. (2020). Perspectives on development of vaccines against severe acute respiratory syndrome coronavirus 2 (SARS-CoV-2). Hum. Vaccin. Immunother. 16, 2366-2369. doi:10.1080/21645515.2020.1787064

Zhang, J., Zeng, H., Gu, J., Li, H., Zheng, L., and Zou, Q. (2020). Progress and prospects on vaccine development against SARS-CoV-2. Vaccines 8, 153. doi:10.3390/vaccines 8020153

Zhu, F.-C., Guan, X.-H., Li, Y.-H., Huang, J.-Y., Jiang, T., Hou, L.-H., et al. (2020a). Immunogenicity and safety of a recombinant adenovirus type-5-vectored COVID-19 vaccine in healthy adults aged 18 years or older: a randomised, double-blind, placebo-controlled, phase 2 trial. The Lancet 396, 479-488. doi:10.1016/s0140-6736(20)31605-6

Zhu, F.-C., Li, Y.-H., Guan, X.-H., Hou, L.-H., Wang, W.-J., Li, J.-X., et al. (2020b). Safety, tolerability, and immunogenicity of a recombinant adenovirus type-5 vectored COVID-19 vaccine: a dose-escalation, open-label, non-randomised, first-in-human trial. The Lancet 395, 1845-1854. doi:10.1016/S0140-6736(20) 31208-3

Zuniga, A., Wang, Z., Liniger, M., Hangartner, L., Caballero, M., Pavlovic, J., et al. (2007). Attenuated measles virus as a vaccine vector. Vaccine 25, 2974-2983. doi:10.1016/j.vaccine.2007.01.064

Conflict of Interest: The authors declare that the research was conducted in the absence of any commercial or financial relationships that could be construed as a potential conflict of interest.

Copyright $\odot 2021$ Bezbaruah, Borah, Kakoti, Al-Shar'I, Chandrasekaran, Jaradat, Al-Zeer and Abu-Romman. This is an open-access article distributed under the terms of the Creative Commons Attribution License (CC BY). The use, distribution or reproduction in other forums is permitted, provided the original author(s) and the copyright owner(s) are credited and that the original publication in this journal is cited, in accordance with accepted academic practice. No use, distribution or reproduction is permitted which does not comply with these terms. 